\title{
Soluble Polymer Precursors via REMP for the Synthesis of Cyclic Polyacetylene
}

Zhihui Miao, ${ }^{1,2}$ Debabrata Konar, ${ }^{2}$ Brent S. Sumerlin, ${ }^{2 *}$ and Adam S. Veige ${ }^{1,2 *}$

1 Center for Catalysis, Department of Chemistry, University of Florida, P.O. Box 117200, Gainesville, Florida 32611, United States

2 George \& Josephine Butler Polymer Research Laboratory, Center for Macromolecular Science \& Engineering, Department of Chemistry, University of Florida, P.O. Box 117200, Gainesville, Florida 32611, United State

*veige@chem.ufl.edu, sumerlin@chem.ufl.edu 


\section{Table of Contents}

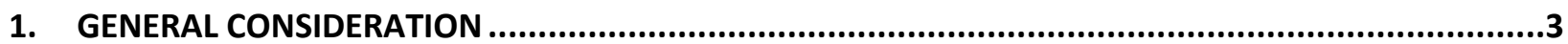

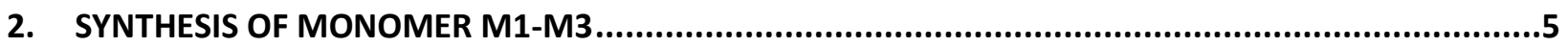

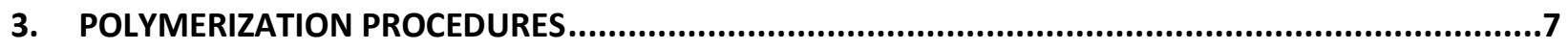

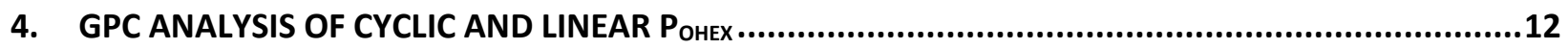

5. FORMATION OF POLYACETYLENE VIA RETRO-DIELS-ALDER REACTION .................................13

6. IR SPECTRA OF C-PA AND L-PA GENERATED FROM CYCLIC AND LINEAR POLYMER PRECURSOR ...15

7. RAMAN SPECTRA OF C-PA AND L-PA GENERATED FROM CYCLIC AND LINEAR POLYMER PRECURSORS

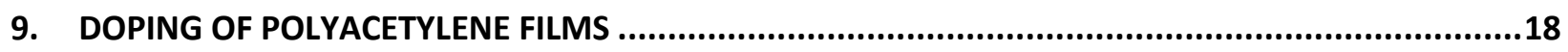

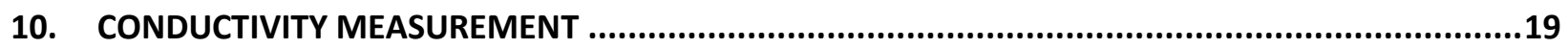

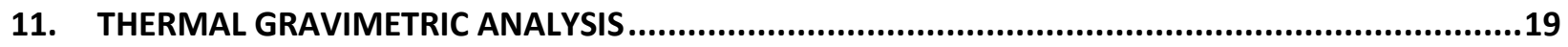

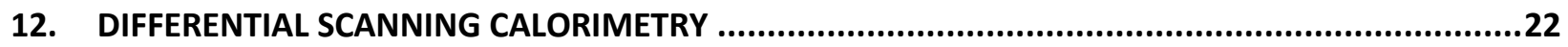

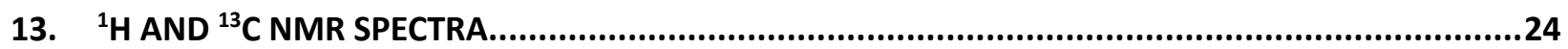




\section{General consideration}

\section{Materials:}

Unless otherwise specified, all manipulations were performed under an inert atmosphere using glove-box techniques. Toluene and THF were dried using a GlassCountour drying column. The following chemical were obtained from commercial sources and used without purification unless otherwise noted: 1,3,5,7-Cyclooctatetraene (Alfa Aesar, 98\%, used further without distillation), p-Benzoquinone (Sigma-Aldrich, 98\%), Hydroquinone (SigmaAldrich, 99\%), iodomethane (Sigma-Aldrich, 99\%), 1-iodohexane (Sigma-Aldrich, 98\%), 1-bromopropane (Sigma-Aldrich, 99\%), 1,2-Dichlorobenzene (Acros Organics, 99\%). $\mathrm{C}_{6} \mathrm{D}_{6}$ (Cambridge Isotopes) and $\mathrm{CDCl}_{3}$ were dried over sodium-benzophenone ketyl, distilled or vacuum transferred, and stored over $3 \AA$ molecular sieves. Anhydrous methanol was purchased from Sigma-Aldrich and bubbled with Ar prior to use. The tungsten catalyst supported by a trianionic pincer ligand (2) was synthesized according to published procedures. ${ }^{1}$ The Grubbs-Hoveyda $2^{\text {nd }}$ generation catalyst was purchased from Sigma-Aldrich and used without further purification.

\section{Analytical techniques:}

${ }^{1} \mathrm{H}$ and ${ }^{13} \mathrm{C}$ NMR spectra were obtained on Varian INOVA spectrometer $(500 \mathrm{MHz})$. Chemical shifts, reported in $\delta(\mathrm{ppm})$, were referenced on the solvent, on the TMS scale for ${ }^{1} \mathrm{H}$ and ${ }^{13} \mathrm{C} .{ }^{1} \mathrm{H}$ NMR spectra were obtained on Bruker Ascend NMR Spectrometer (400 MHz). CDCl3 was used as the solvent. Chemical shifts were reported in $\delta(p p m)$,

referenced on the solvent, on the TMS scale for ${ }^{1} \mathrm{H}$. The spectra were recorded at $25^{\circ} \mathrm{C}$ unless noted otherwise. Gel permeation chromatography (GPC) was performed in THF at $35^{\circ} \mathrm{C}$ and a flow rate of $1.0 \mathrm{~mL} / \mathrm{min}$ (Agilent isocratic pump, degasser, and autosampler; 
columns: three PLgel $5 \mu \mathrm{m}$ MIXED-D mixed bed columns, molecular weight range $200-400,000 \mathrm{~g} / \mathrm{mol})$. Detection consisted of a Wyatt Optilab rEX refractive index detector operating at $658 \mathrm{~nm}$, a Wyatt miniDAWN Treos light scattering detector operating at 656 $\mathrm{nm}$, and a Wyatt ViscoStar-II viscometer. Absolute molecular weights and molecular weight distributions were calculated using the Wyatt ASTRA software). Thermogravimetric analyses (TGA) were measured under nitrogen with a TGA Q5000 (TA Instruments). About 10-15 mg of each sample was dried under dynamic vacuum for $24 \mathrm{~h}$. Then, $5 \mathrm{mg}$ portions of these samples were heated at $20^{\circ} \mathrm{C} / \mathrm{min}$ from 25 to $600{ }^{\circ} \mathrm{C}$. Thermogravimetric analyses coupled with mass-spectrometer (TGA-MS) were measured under nitrogen with a TGA Q5000 coupled with DMS Series II mass spectrometer (TA Instruments). About 10-15 mg of each sample was dried under dynamic vacuum for 24 h. Then, $1 \mathrm{mg}$ portions of these samples were heated at $20^{\circ} \mathrm{C} / \mathrm{min}$ from 0 to $600{ }^{\circ} \mathrm{C}$. Differential scanning calorimetry (DSC) thermograms were obtained with a DSC Q1000 (TA instruments). Typically, 4-6 mg of a sample was massed and added to a sealed pan to heat at $5{ }^{\circ} \mathrm{C} / \mathrm{min}$. Reported data are from the second full cycle. The temperature ranged from 30 to $170{ }^{\circ} \mathrm{C}$. Infrared spectra were collected on a Thermo Nicolet 5700 FT-IR spectrometer equipped with a single bounce; diamond-stage attenuated total reflectance (ATR) accessory. The Raman spectroscopies were recorded on a Horiba Aramis Raman system with a $10 \times$ object lens. Lasers with wavelengths of $532 \mathrm{~nm}, 633 \mathrm{~nm}$, and $785 \mathrm{~nm}$ and $1800 \mathrm{~g} / \mathrm{mm}$ gratings were used. The sheet resistivities of the films were measured on a Signatone Pro4-4400 4-point probe station equipped with a Keithley 2400 source meter. The thickness was measured using a profilometer. 
2. Synthesis of monomer M1-M3

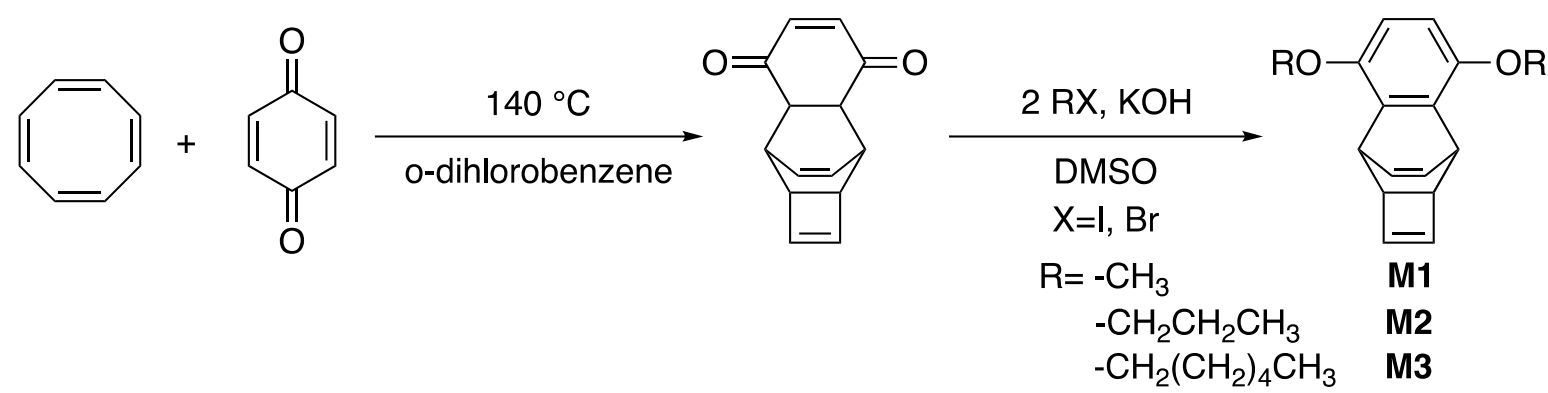

Scheme S1. General route for the synthesis of dialkoxybenzotricyclodecatriene monomers.

2.1. Synthesis of Cyclobutanaphthalene-4,7-dione:

Cyclooctatetraene $(6.00 \mathrm{~g}, 57.61 \mathrm{mmol}, 1$ equiv), benzoquinone $(9.96 \mathrm{~g}, 92.17 \mathrm{mmol}, 1.6$ equiv), and hydroquinone (0.032 $\mathrm{g}, 0.29 \mathrm{mmol}, 0.005$ equiv) were dissolved in odichlorobenzene $(76 \mathrm{~mL})$ in a $500 \mathrm{~mL}$ round-bottom flask fitted with a reflux condenser. The reaction mixture was stirred at $140{ }^{\circ} \mathrm{C}$ for 6 hours. The flask was cooled down to room temperature and the o-dichlorobenzene was removed under vacuum at elevated temperatures $\left(80^{\circ} \mathrm{C}\right)$. The crude product was obtained as a greenish-black solid. The desired product was obtained by recrystallization of the crude compound in hot ethanol and storing the flask overnight at $-5{ }^{\circ} \mathrm{C}$. The resulting brown crystals were filtered and dried under vacuum, yielding cyclobutanaphthalene-4,7-dione. ${ }^{1} \mathrm{H} \mathrm{NMR}\left(\mathrm{CDCl}_{3}, 600 \mathrm{MHz}\right)$ $\delta(\mathrm{ppm}): \delta 6.64(\mathrm{~s}, 2 \mathrm{H}), 5.93-5.88(\mathrm{~m}, 2 \mathrm{H}), 5.83(\mathrm{~s}, 2 \mathrm{H}), 3.20(\mathrm{~s}, 2 \mathrm{H}), 2.85(\mathrm{~d}, J=9.0$ $\mathrm{Hz}, 4 \mathrm{H}) .{ }^{13} \mathrm{C} \mathrm{NMR}\left(\mathrm{CDCl}_{3}, 151 \mathrm{MHz}\right) \delta$ (ppm): 199.20, 141.87, 138.02, 129.49, 48.07, $44.64,40.51$.

2.2. Synthesis of $\mathbf{M} \mathbf{1}$ :

Cyclobutanaphthalene-4,7-dione (1.20 g, $5.65 \mathrm{mmol}, 1$ equiv) and potassium hydroxide $(0.760 \mathrm{~g}, 13.57 \mathrm{mmol}, 2.4$ equiv) were placed in a $100 \mathrm{~mL}$ round bottom flask and 
dissolved in DMSO $(20 \mathrm{~mL})$ at room temperature. Methyl iodide $(2.11 \mathrm{~mL}, 33.92 \mathrm{mmol}, 6$ equiv) was added, and the reaction was stirred for 3 hours. Then additional methyl iodide $(1 \mathrm{~mL})$ was added, and the reaction was stirred overnight. The completion of the reaction was monitored by TLC analysis (Diethyl ether/Hexane $=0.3 / 10$ ). The reaction mixture was poured into cold water (4 times the reaction volume) and extracted with dichloromethane $(4 \times 20 \mathrm{~mL})$. The organic layer was washed with brine solution, dried with anhydrous sodium sulfate and filtered. After evaporation, the residue was purified via flash column chromatography on silica gel $\left(\mathrm{Et}_{2} \mathrm{O} / \mathrm{Hexane}=0.3 / 10\right)$ to obtain the desired product as a white solid (62\% yield, $0.835 \mathrm{~g}) .{ }^{1} \mathrm{H}$ NMR $\left(\mathrm{CDCl}_{3}, 600 \mathrm{MHz}\right) \delta(\mathrm{ppm}): 6.62(\mathrm{~s}$, 2H), 6.24 (dd, $J=4.6,3.3 \mathrm{~Hz}, 2 \mathrm{H}$ ), 6.09 (s, 2H), 4.27 (dq, $J=4.6,3.2,2.2 \mathrm{~Hz}, 2 \mathrm{H}$ ), 3.80 (s, 6H), $2.62(\mathrm{~d}, J=2.4 \mathrm{~Hz}, 2 \mathrm{H}) \cdot{ }^{13} \mathrm{C} \mathrm{NMR}\left(\mathrm{CDCl}_{3}, 151 \mathrm{MHz}\right) \delta(\mathrm{ppm}):$ 149.23, 138.81, $133.58,131.30,108.51,56.37,45.56,37.64$.

\subsection{Synthesis of $\mathbf{M} 2$ :}

Cyclobutanaphthalene-4,7-dione $(0.465 \mathrm{~g}, 2.19 \mathrm{mmol}, 1$ equiv) and potassium hydroxide ( $0.295 \mathrm{~g}, 5.25 \mathrm{mmol}, 2.4$ equiv) were placed in a $100 \mathrm{~mL}$ round bottom flask and dissolved in DMSO at room temperature. Propyl bromide $(1.19 \mathrm{~mL}, 13.14 \mathrm{mmol}, 6$ equiv) was added, and the reaction was stirred for 3 hours. Then additional propyl bromide $(0.6 \mathrm{~mL})$ was added, and the reaction was stirred overnight. The completion of the reaction was monitored by TLC analysis (Diethyl ether/Hexane $=0.3 / 10$ ). The reaction mixture was poured into cold water (4 times the reaction volume) and extracted with dichloromethane $(4 \times 20 \mathrm{~mL})$. The organic layer was washed with brine solution, dried with anhydrous sodium sulfate and filtered. After evaporation, the residue was purified via flash column chromatography on silica gel $\left(\mathrm{Et}_{2} \mathrm{O} / \mathrm{Hexane}=0.3 / 10\right)$ to obtain the desired product as a 
white solid (62\% yield, 0.398g). ${ }^{1} \mathrm{H}$ NMR $\left(\mathrm{CDCl}_{3}, 600 \mathrm{MHz}\right) \delta(\mathrm{ppm}): 6.59(\mathrm{~s}, 2 \mathrm{H}), 6.27-$ $6.20(\mathrm{~m}, 2 \mathrm{H}), 6.09(\mathrm{~s}, 2 \mathrm{H}), 4.37-4.18(\mathrm{~m}, 2 \mathrm{H}), 3.94-3.82(\mathrm{~m}, 4 \mathrm{H}), 2.62(\mathrm{~s}, 2 \mathrm{H}), 1.80(\mathrm{~h}$, $J=7.2 \mathrm{~Hz}, 4 \mathrm{H}), 1.05(\mathrm{t}, J=7.4 \mathrm{~Hz}, 6 \mathrm{H}) .{ }^{13} \mathrm{C} \mathrm{NMR}\left(\mathrm{CDCl}_{3}, 151 \mathrm{MHz}\right) \delta(p p m): 148.72$, $138.86,133.96,131.35,110.35,71.16,45.66,37.69,23.00,10.78$.

\subsection{Synthesis of M3:}

Cyclobutanaphthalene-4,7-dione (1.20 g, $5.65 \mathrm{mmol}, 1$ equiv) and potassium hydroxide $(0.760 \mathrm{~g}, 13.57 \mathrm{mmol}, 2.4$ equiv) were placed in a $100 \mathrm{~mL}$ round bottom flask and dissolved in DMSO $(20 \mathrm{~mL})$ at room temperature. Hexyl iodide $(5 \mathrm{~mL}, 33.92 \mathrm{mmol}, 6$ equiv) was added, and the reaction was stirred for 3 hours. Then additional hexyl iodide (2.5 $\mathrm{mL})$ was added, and the reaction was stirred overnight. The completion of the reaction was monitored by TLC analysis (Diethyl ether/Hexane $=0.3 / 10$ ). The reaction mixture was poured into cold water (4 times the reaction volume) and extracted with dichloromethane $(4 \times 20 \mathrm{~mL})$. The organic layer was washed with brine solution, dried with anhydrous sodium sulfate and filtered. After evaporation, the residue was purified via flash column chromatography on silica gel $\left(\mathrm{Et}_{2} \mathrm{O} / \mathrm{Hexane}=0.3 / 10\right)$ to obtain the desired product as a white solid (62\% yield, 1.337g). ${ }^{1} \mathrm{H} \mathrm{NMR}\left(\mathrm{CDCl}_{3}, 600 \mathrm{MHz}\right) \delta(\mathrm{ppm}): 6.59(\mathrm{~s}$, 2H), 6.23 (dd, $J=4.5,3.3 \mathrm{~Hz}, 2 \mathrm{H}), 6.09(\mathrm{~s}, 2 \mathrm{H}), 4.27(\mathrm{dq}, J=4.5,3.1,2.1 \mathrm{~Hz}, 2 \mathrm{H}), 4.03$ - $3.77(\mathrm{~m}, 4 \mathrm{H}), 2.62(\mathrm{~d}, J=2.3 \mathrm{~Hz}, 2 \mathrm{H}), 1.78(\mathrm{dt}, J=14.5,6.6 \mathrm{~Hz}, 4 \mathrm{H}), 1.48(\mathrm{p}, J=7.3$ $\mathrm{Hz}, 4 \mathrm{H}), 1.35(\mathrm{dt}, J=7.1,3.6 \mathrm{~Hz}, 8 \mathrm{H}), 0.98-0.85(\mathrm{~m}, 6 \mathrm{H}) .{ }^{13} \mathrm{C} \mathrm{NMR}\left(\mathrm{CDCl}_{3}, 151 \mathrm{MHz}\right) \delta$ (ppm): 148.72, 138.86, 133.92, 131.34, 110.30, 69.63, 45.67, 37.70, 31.78, 29.64, 25.98, $22.80,14.21$.

3. Polymerization procedures

3.1. Synthesis of cyclic polymer precursors 


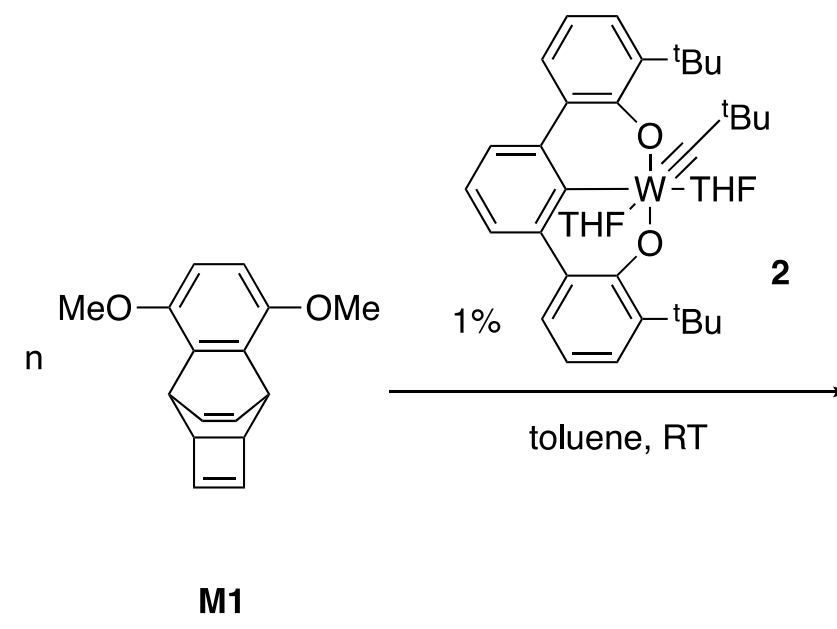

Scheme S2. Synthesis of $\boldsymbol{c}$-Pome.

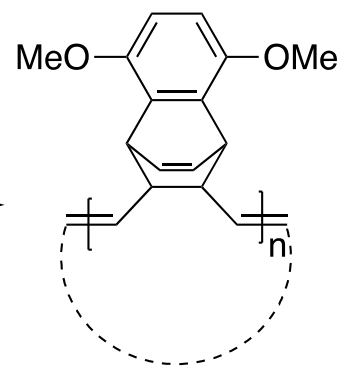

c-Pome

In an inert atmosphere glovebox, dissolving $200.0 \mathrm{mg}$ M1 monomer with $5.0 \mathrm{~mL}$ toluene in a glass vial equipped with a stir bar afforded a colorless monomer solution. Addition of $1.28 \mathrm{~mL}$ of catalyst 1 bulk solution $(5 \mathrm{mg} / \mathrm{mL})$ in one shot initiated the polymerization. The solution turned from red orange (catalyst color) to green immediately, then slowly turned cloudy and yellow over the next few hours. After $24 \mathrm{~h}$, the polymerization solution was yellow with white precipitates formed. The vial was then taken out of the box and the solution was drop-wisely added to tenfold excess of stirring degassed methanol. The precipitates were also transferred into the stirring methanol solution. Vacuum filtration followed by drying under vacuum overnight gave $\boldsymbol{c}$-Pome as a slight yellow solid in $96 \%$ yield. The solid exhibits very low solubility in $\mathrm{CDCl}_{3}$ and $\mathrm{C}_{6} \mathrm{D}_{6}$.

$\boldsymbol{c}$-Popr and $\boldsymbol{c}$-Poнex were synthesized using the same approach. $\boldsymbol{c}$-PoPr was obtained in $98 \%$ yield with $24 \mathrm{~h}$ polymerization with $1.0 \mathrm{~mol} \%$ catalyst loading in toluene. It also exhibits low solubility $\mathrm{CDCl}_{3}$ and $\mathrm{C}_{6} \mathrm{D}_{6}$.

. c-PoHex was obtained in $86 \%$ yield with $48 \mathrm{~h}$ polymerization with $1.0 \mathrm{~mol} \%$ catalyst loading in toluene. $\boldsymbol{c}$-PoHex is readily soluble in $\mathrm{CDCl}_{3}{ }^{1} \mathrm{H} \mathrm{NMR}\left(\mathrm{CDCl}_{3}, 500 \mathrm{MHz}\right) \delta(\mathrm{ppm})$ : 6.9-6.4 (b, 2H, Ar- $H), 6.4-6.0\left(\mathrm{bm}, 2 \mathrm{H},=\mathrm{C}_{\text {bridge }} H\right)$, 5.9-4.9 (b, 2H, =Cbackbone $\left.H\right)$, 4.7-402 (b, 
$2 \mathrm{H}, \mathrm{CH}), 4.0-3.2\left(\mathrm{bm}, 4 \mathrm{H}, \mathrm{OCH}_{2}\right), 3.2-2.3(\mathrm{~b}, 2 \mathrm{H}$, Cbackbone- $H), 2.1-0.4(\mathrm{bd}, 22 \mathrm{H}$, $\left.\mathrm{OCH}_{2} \mathrm{C}_{5} \mathrm{H}_{11}\right)$.

3.2. Synthesis of linear polymer precursors

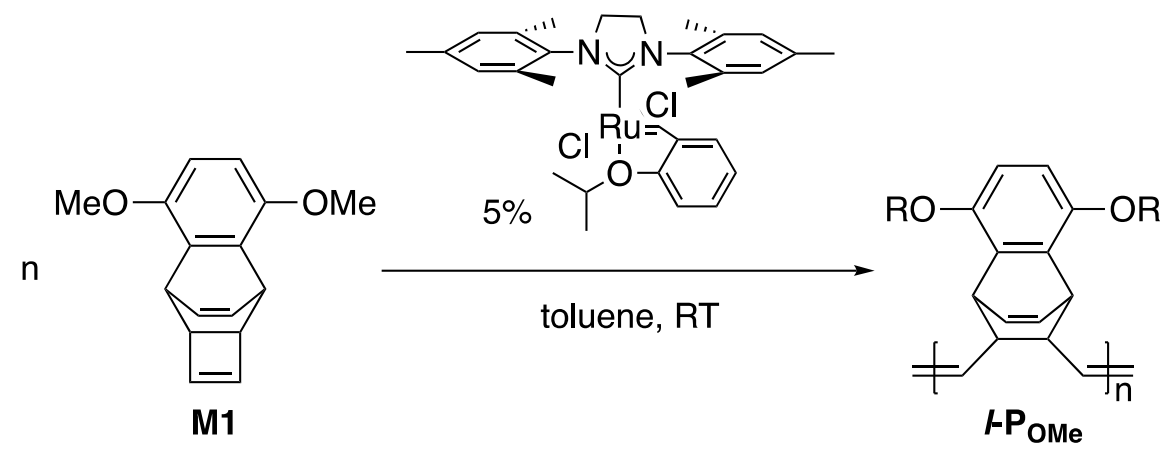

Scheme S3. Synthesis of $I$-Pome.

Dissolving $200.0 \mathrm{mg}$ M1 monomer with $5.0 \mathrm{~mL}$ toluene in a glass vial equipped with a stir bar afforded a colorless monomer solution. Addition of Grubbs-Hoveyda $2^{\text {nd }}$ catalyst bulk solution in one shot initiated the polymerization. The solution turned yellow, then slowly turned cloudy and white precipitates slowly formed within $1 \mathrm{~h}$. After $6 \mathrm{~h}$, the polymerization solution was yellow with white precipitates formed. The vial was then taken out of the box and the solution was drop-wisely added to tenfold excess of stirring degassed methanol. The precipitates were also transferred into the stirring methanol solution. Vacuum filtration followed by drying under vacuum overnight gave cyclic polymer as a slight yellow solid in $91 \%$ yield. The solid exhibits very low solubility in $\mathrm{CDCl}_{3}$ and $\mathrm{C}_{6} \mathrm{D}_{6}$.

I-PoPr and I-PoHex were synthesized using the same approach. I-PoPr also exhibits low solubility $\mathrm{CDCl}_{3}$ and $\mathrm{C}_{6} \mathrm{D}_{6}$.

I-PoHex is readily soluble in $\mathrm{CDCl}_{3} .{ }^{1} \mathrm{H} \mathrm{NMR}\left(\mathrm{CDCl}_{3}, 500 \mathrm{MHz}\right) \delta(\mathrm{ppm}): 7.5-6.7(\mathrm{bs}, 2 \mathrm{H}$, Ar- $H)$, 6.7-6.3 (bm, 2H, =C bridge $H)$, 5.7-5.1 (bm, 2H, =C backbone $H), 4.7-4.2(\mathrm{bm}, 2 \mathrm{H}, \mathrm{CH})$, 
4.1-3.5(bm, 4H, OCH$)$, 3.2-2.3 (bd, $\left.2 \mathrm{H}, \mathrm{C}_{\text {backbone- }} \mathrm{H}\right)$, 2.2-1.6 (bd, $\left.4 \mathrm{H}, \mathrm{OCH}_{2} \mathrm{CH}_{2}\right), 1.6-1.0$ (bm, $\left.12 \mathrm{H}, \mathrm{C}_{3} \mathrm{H}_{6}-\mathrm{CH}_{3}\right), 1.0-0.5$ (bs, $6 \mathrm{H}, \mathrm{CH}_{3}$ ).

\subsection{IR spectra}

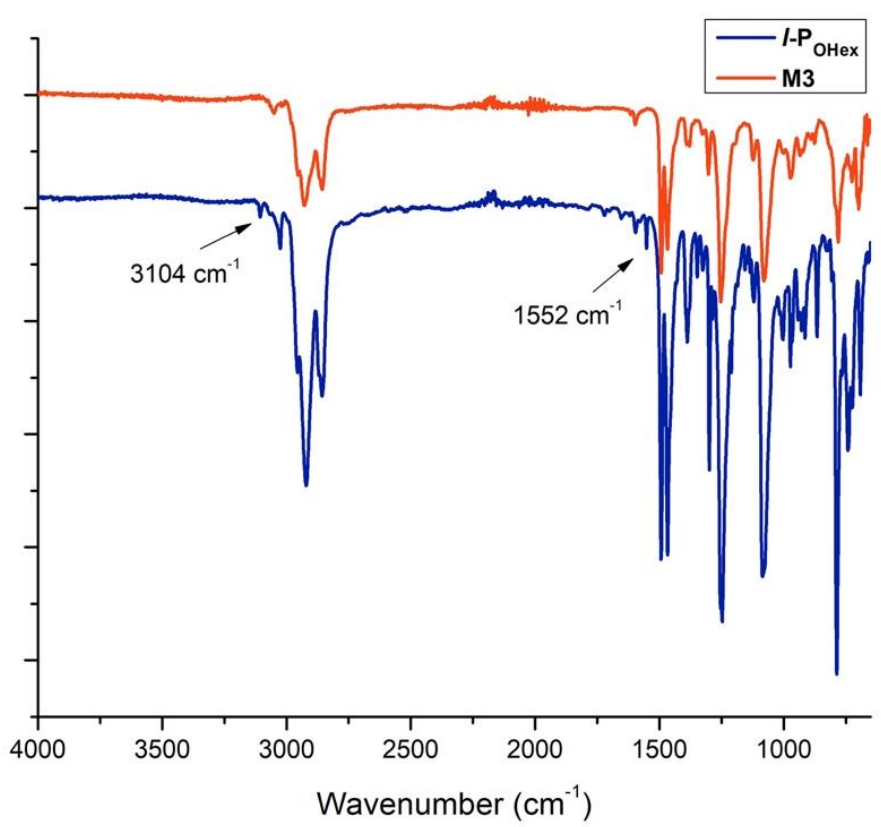

Figure S1. IR spectra comparison of monomer M3 (blue) and I-PoHex (orange).

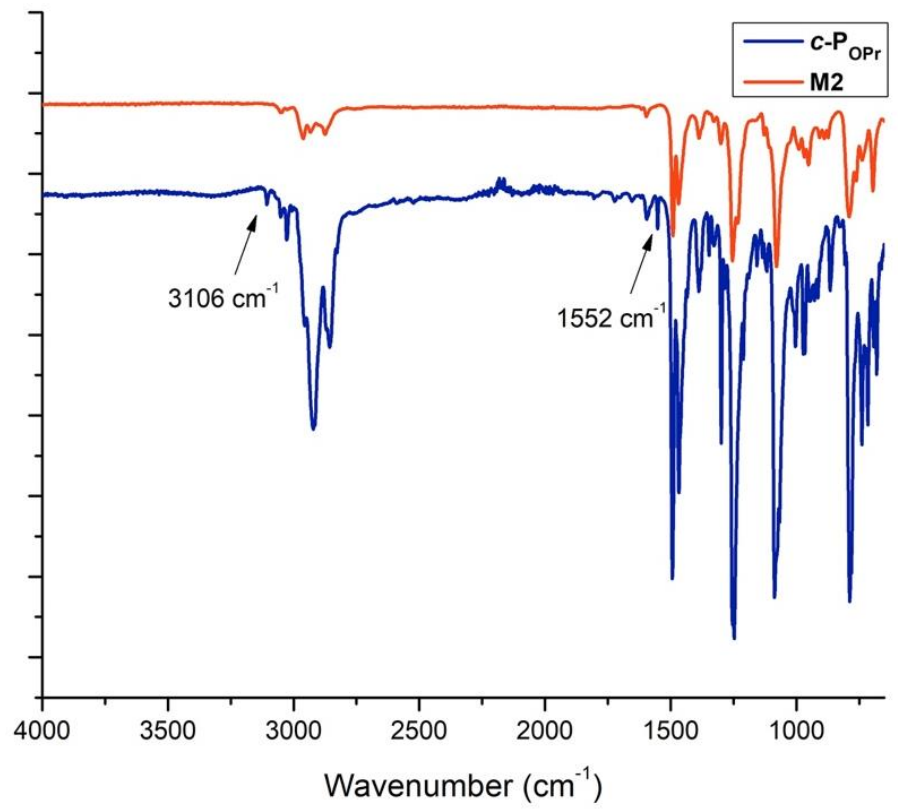

Figure S2. IR spectra comparison of monomer M2 (blue) and c-PoPr (orange). 


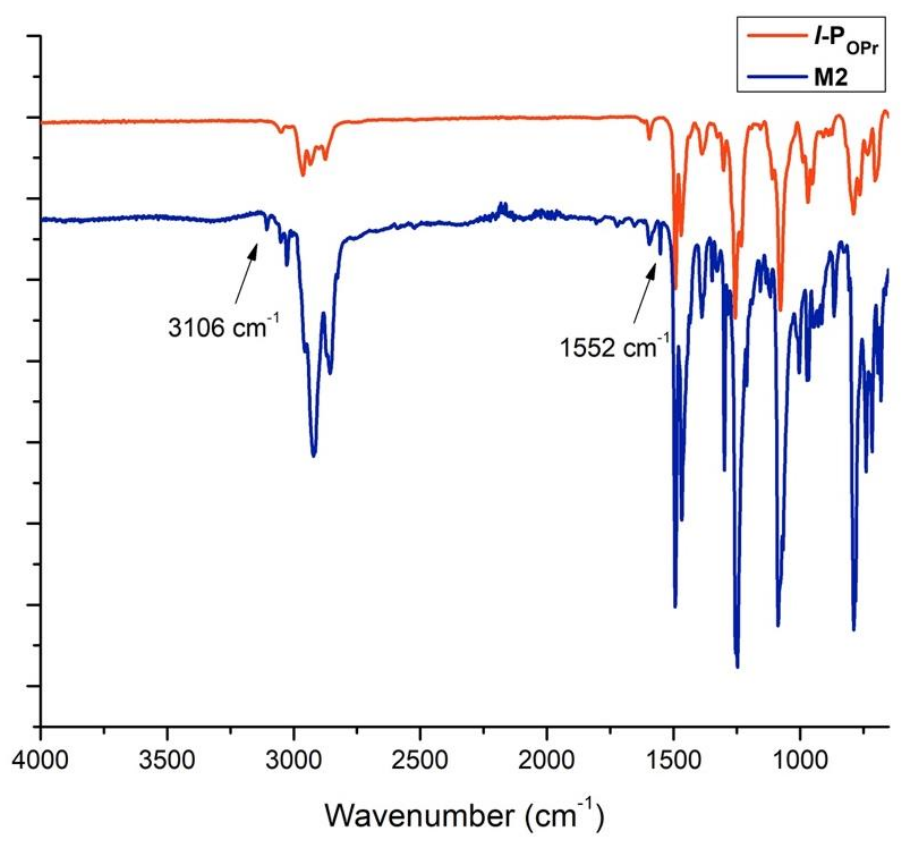

Figure S3. IR spectra comparison of monomer M2 (blue) and I-PoPr (orange).

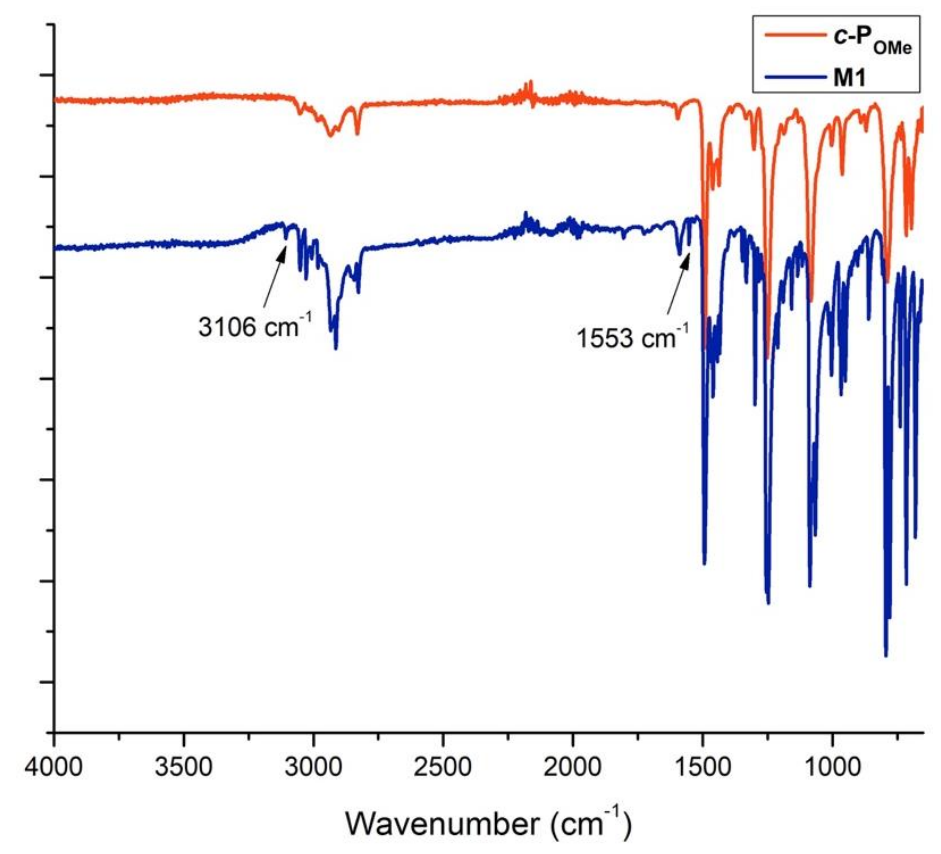

Figure S4. IR spectra comparison of monomer M1 (blue) and c-Pome (orange). 


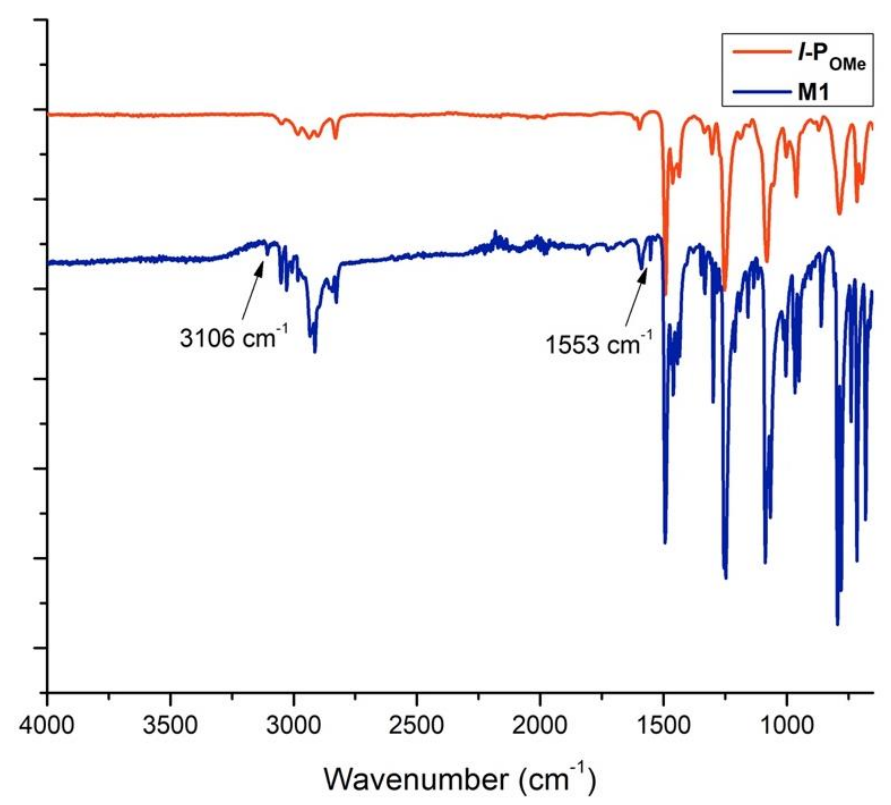

Figure S5. IR spectra comparison of monomer M1 (blue) and I-Pome (orange).

4. GPC analysis of cyclic and linear PoHex

The absolute molecular weight averages and distribution of the polymer samples were measured by size-exclusion chromatography coupled with light scattering. $2.0 \mathrm{mg}$ of polymer sample was dissolved in $1.0 \mathrm{~mL}$ THF. The $\mathrm{dn} / \mathrm{dc}$ value was measured using $100 \%$ mass recovery method with exact concentration of the polymer solution.

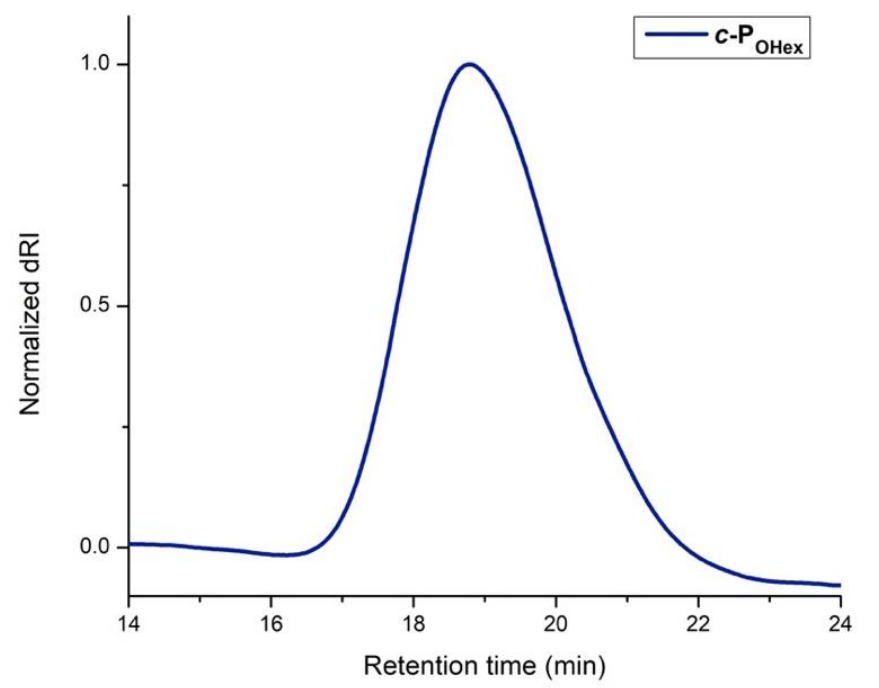

Figure S6. GPC trace of $\boldsymbol{c}$-PoHex in THF at $35^{\circ} \mathrm{C}$. 


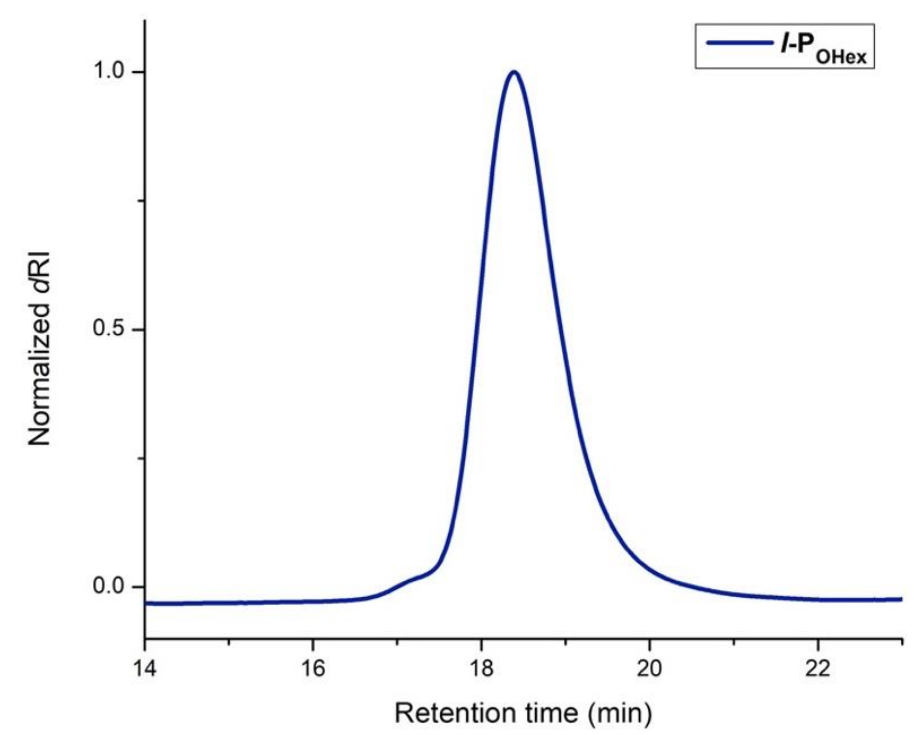

Figure S7. GPC trace of $\boldsymbol{l}-\mathrm{PoHex}_{\text {in }} \mathrm{THF}$ at $35^{\circ} \mathrm{C}$.

5. Formation of polyacetylene via retro-Diels-Alder reaction

\subsection{Bulk polyacetylene}
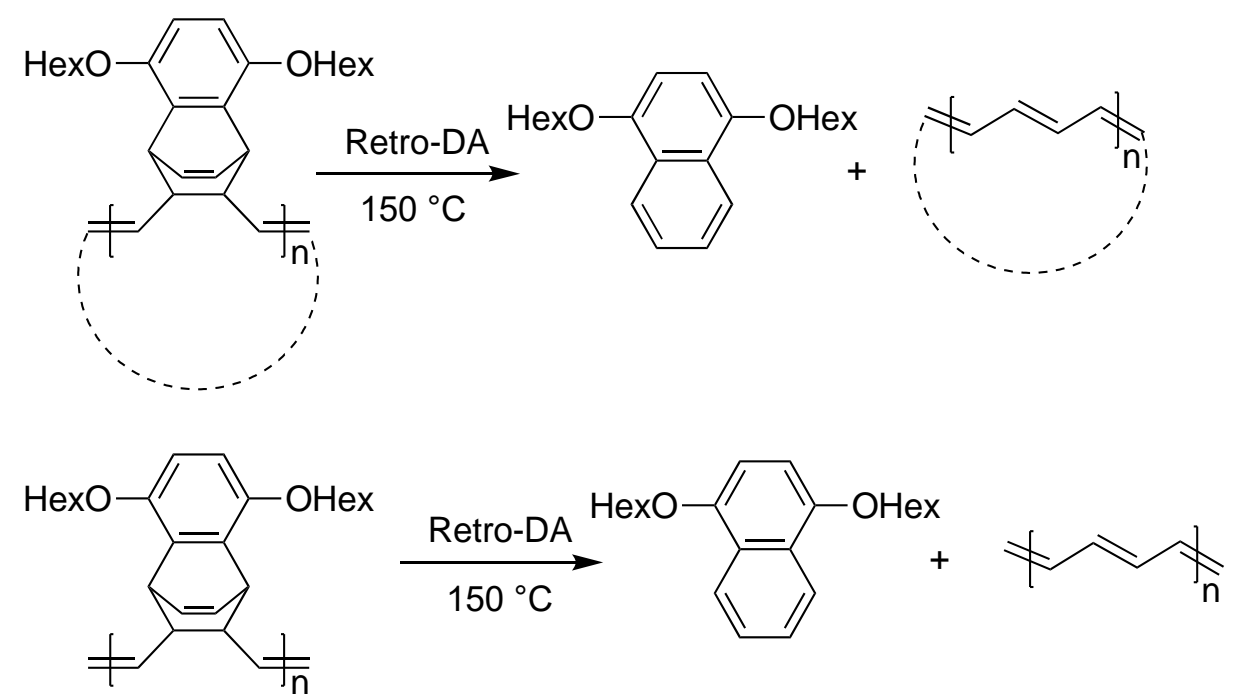

Scheme S4. Synthesis of $\boldsymbol{c}$-PA and $\boldsymbol{I}$-PA from $\boldsymbol{c}$ - and $\boldsymbol{I}$-PoHex, respectively

Cyclic polymer is put into sealed vials in a glovebox. It is then taken out of the box and heated at $150{ }^{\circ} \mathrm{C}$ for $30 \mathrm{~min}$. The solid turns orange, then red, and finally black within 5 min. After 30 min, white solids were sublimed on the top part of the vial, leaving black solid at the bottom. The vial was then taken into the box and the black solid was rinsed 
with THF 5 times followed by pentane washes. The black solid was dried under dynamic vacuum. The filtrate was collected, and the solvents were removed under vacuum to produce the eliminated 1,4-bis(methoxy)naphthalene as a white solid. ${ }^{1} \mathrm{H}$ NMR $\left(\mathrm{CDCl}_{3}\right.$, $500 \mathrm{MHz}) \delta$ (ppm): 8.24 (dd, 2H, Ar-H), 7.49 (dd, 2H, Ar-H), 6.68 (s, 2H, HexO-Ar-H)4.08 (t, 2H, OCH$)_{2}, 1.90\left(\mathrm{~m}, 2 \mathrm{H}, \mathrm{OCH}_{2} \mathrm{CH}_{2}\right), 1.90\left(\mathrm{~m}, 2 \mathrm{H}, \mathrm{OCH}_{2} \mathrm{CH}_{2} \mathrm{CH}_{2}\right), 1.39\left(\mathrm{~m}, \mathrm{C}_{2} \mathrm{H}_{4}-\mathrm{CH}_{3}\right)$, $0.92\left(\mathrm{t}, 3 \mathrm{H}, \mathrm{CH}_{3}\right)$.

\subsection{Polyacetylene film}

PoHex polymers were dissolved in THF, then solvent casted as a film onto a glass slide. The film was put under dynamic vacuum to dry and then transferred into a glovebox, where it was sealed into a vial. The vial was then taken out of the glovebox and heated at $150{ }^{\circ} \mathrm{C}$ for $30 \mathrm{~min}$. The film turns orange, red, then black within $5 \mathrm{~min}$. During the 30 min heating, there were obvious cracks occurred with the film. Brown solids formed on the film. The vial then was brought into the glovebox and the glass slide with the films were carefully washed with THF and pentane. The pieces of films were then dried under dynamic vacuum to yield black PA films. 
6. IR spectra of $\boldsymbol{c}$-PA and I-PA generated from cyclic and linear polymer precursor

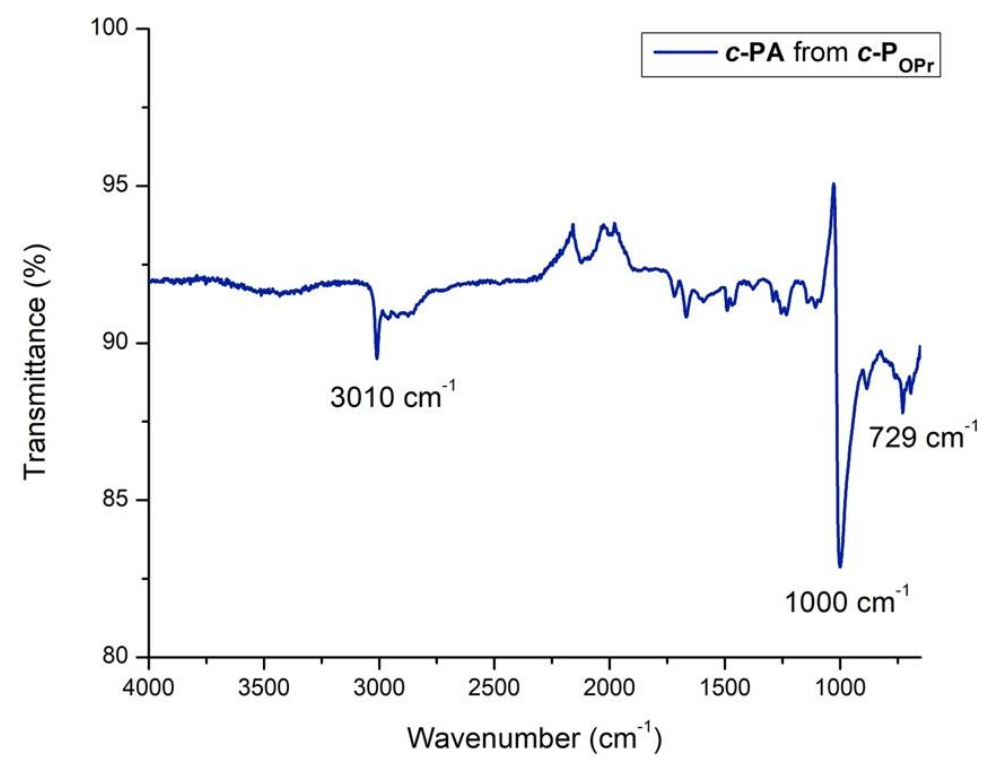

Figure S8. IR spectrum of $\boldsymbol{c}$-PA generated from $\boldsymbol{c}$-PoPr.

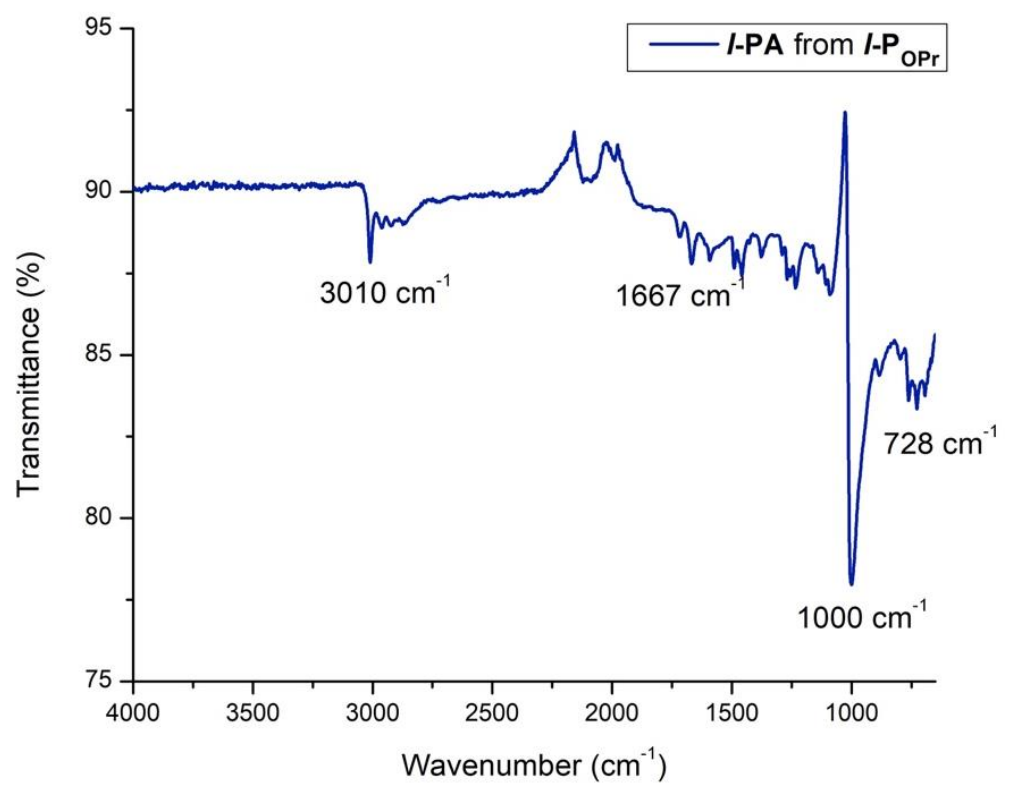

Figure S9. IR spectrum of I-PA generated from I-PoPr. 


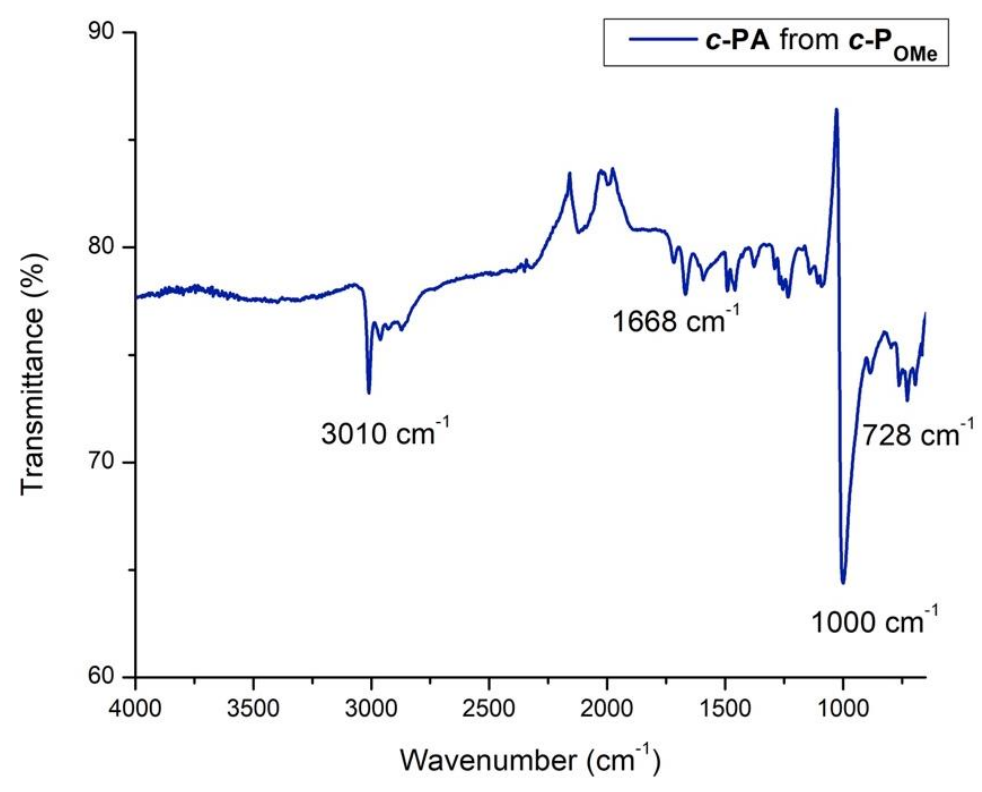

Figure S10. IR spectrum of $\boldsymbol{c}$-PA generated from $\boldsymbol{c}$-Pome.

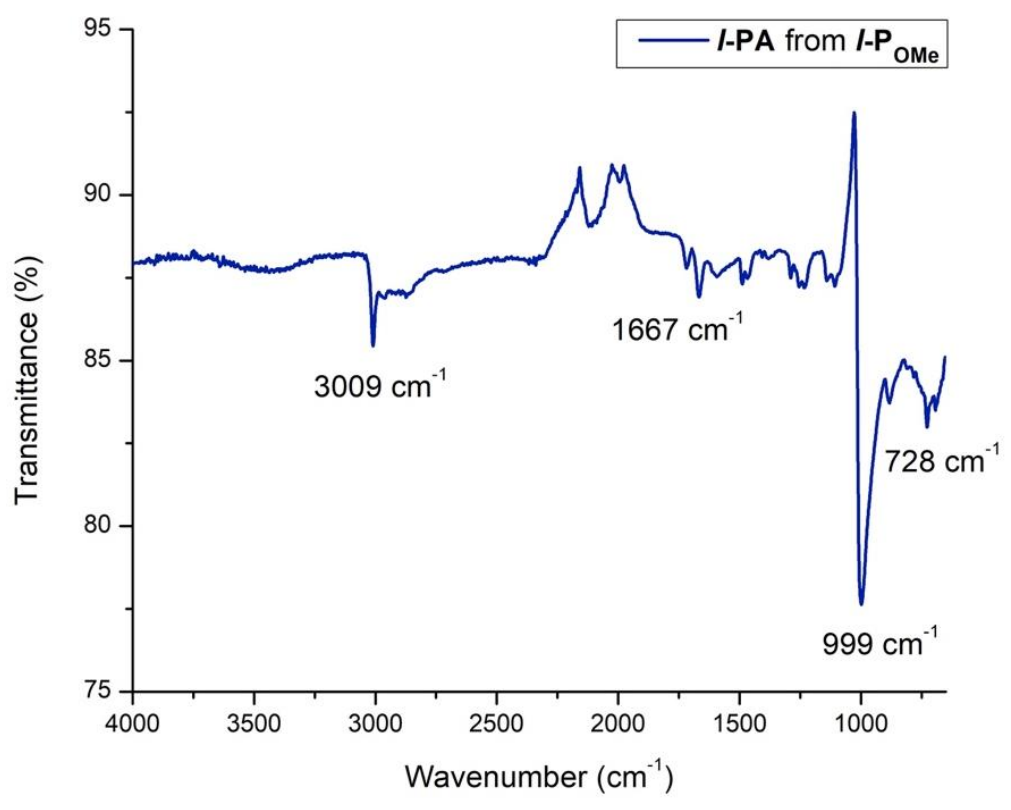

Figure S11. IR spectrum of I-PA generated from I-Pome. 
7. Raman spectra of $\boldsymbol{c}$-PA and $\boldsymbol{I}$-PA generated from cyclic and linear polymer precursors

Different excitation lasers with wavelength of 785,633 , and $532 \mathrm{~nm}$ were used. Raman spectra of $\boldsymbol{c}$-PA and I-PA generated from cyclic and linear PoHex and PoPr were recorded respectively with filter number of 0.6 , a hole size of $200 \mu \mathrm{m}, 1800 \mathrm{~g} / \mathrm{mm}$ grating type, $1 \mathrm{~s}$ continuous mode time, and $1 \mathrm{~s}$ snapshot time with different lasers.

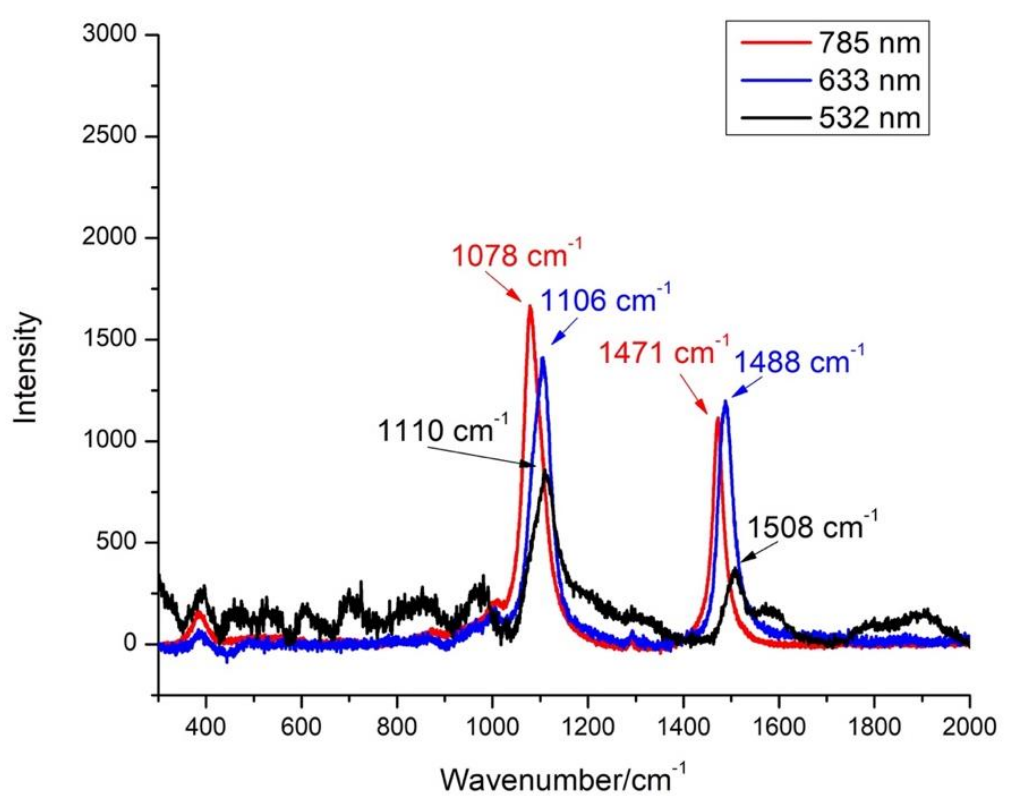

Figure S12. Raman spectra of $\boldsymbol{c}$-PA generated from $\boldsymbol{c}$-Pome. 


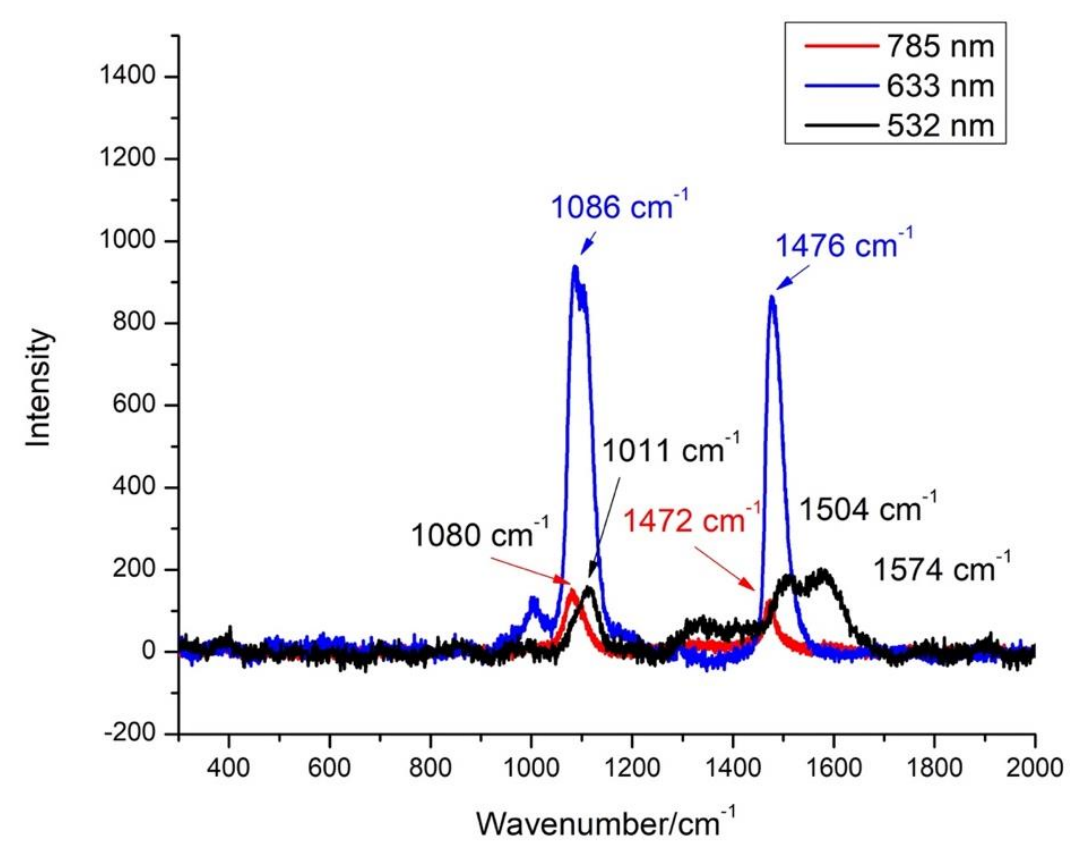

Figure S13. Raman spectra of $\boldsymbol{l}$-PA generated from $\boldsymbol{l}$-Pome.

8. Equations to calculate conjugation lengths based on Raman frequencies
$\omega=(1438+830 / \mathrm{N}) \mathrm{cm}^{-1}$ Schaffer et al. ${ }^{2}$
$\omega=(1440+830 / \mathrm{N}) \mathrm{cm}^{-1}$ Chance et al. ${ }^{3}$
$\omega=(1430+840 / \mathrm{N}) \mathrm{cm}^{-1}$ Schaffer et al. ${ }^{4}$
$\omega=(1450+500 / \mathrm{N}) \mathrm{cm}^{-1}$ Brivio et al. ${ }^{5}$

9. Doping of polyacetylene films

The polymer films were exposed to $I_{2}$ in an evacuated iodine chamber for $3 \mathrm{~h}$. The excess $I_{2}$ was removed by placing the films under dynamic vacuum overnight. The iodine doping percentages were calculated based on the weights before and after doping. 


\section{Conductivity measurement}

Measuring the sheet resistivity using a 4-point probe station and measuring the thickness with a profilometer gave the resistivity of the PA films. The conductivity was calculated as $1 /$ resistivity.

11. Thermal gravimetric analysis

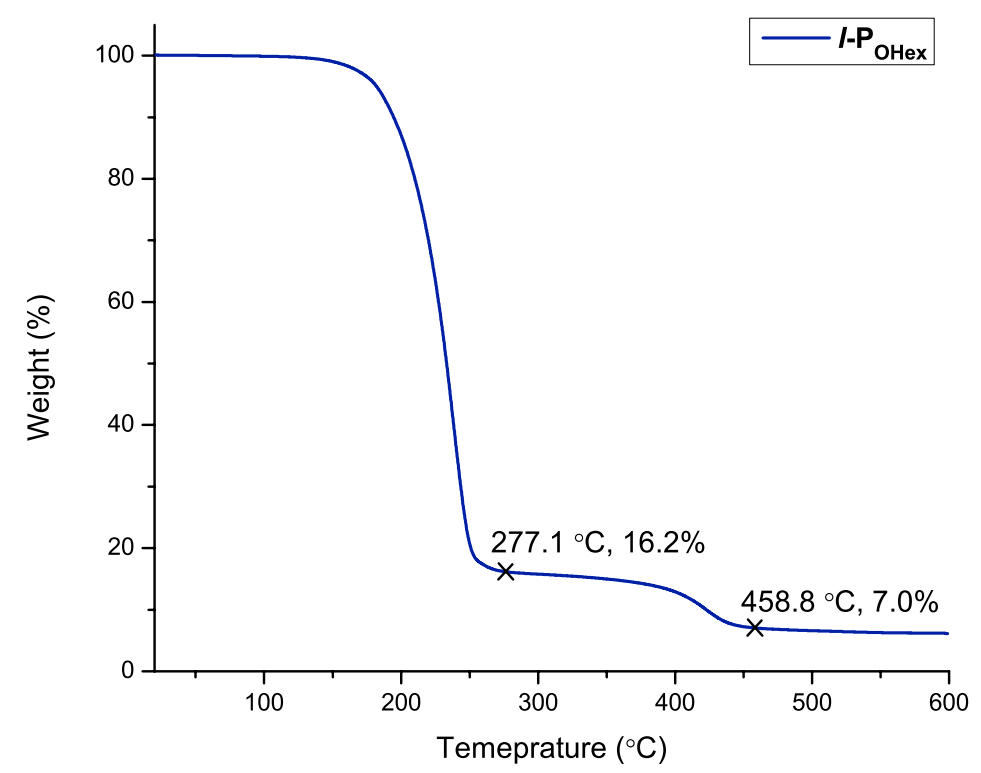

Figure S14. TGA curve of $I$-PoHex. 


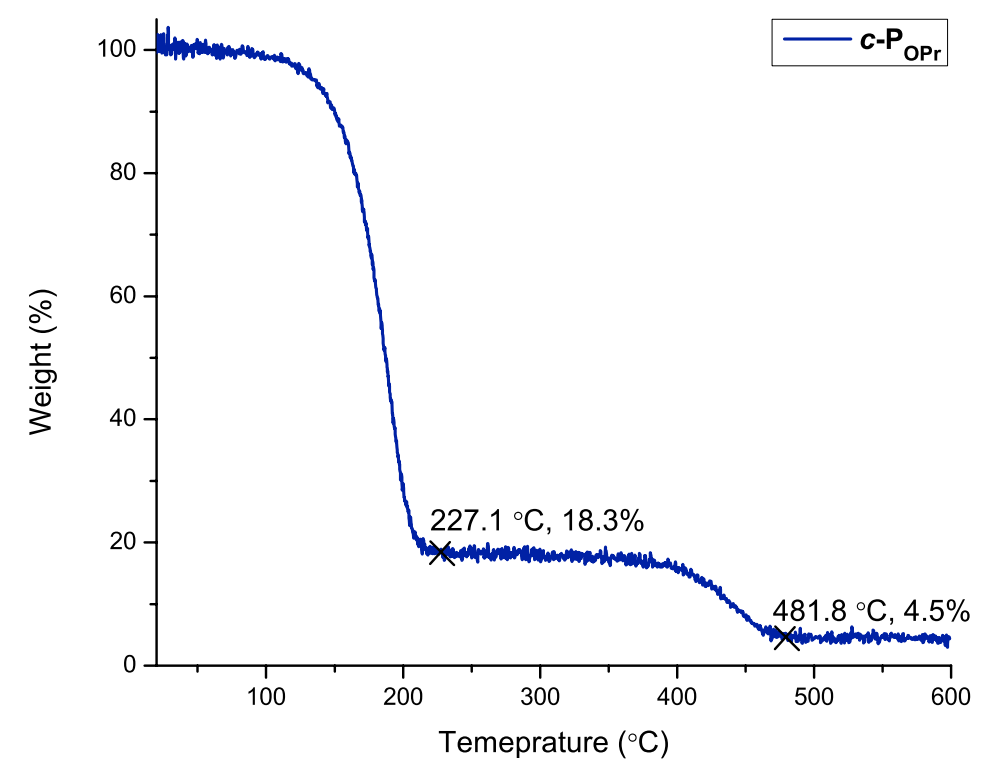

Figure S15. TGA curve of $c$-PoPr.

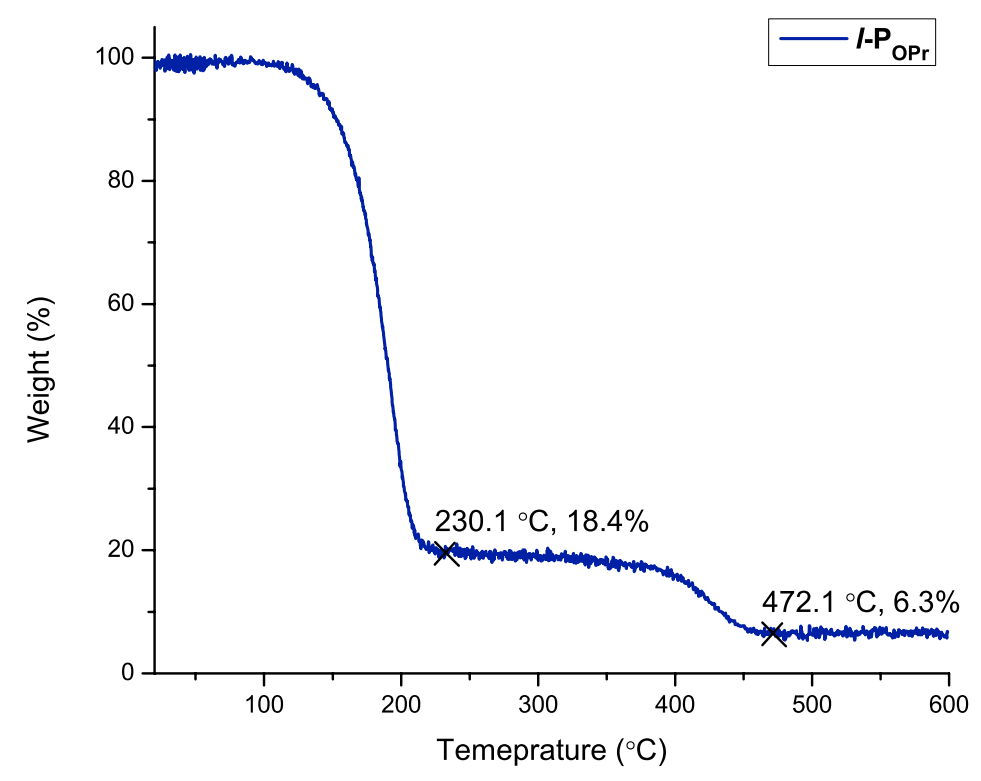

Figure S16. TGA curve of I-Popr. 


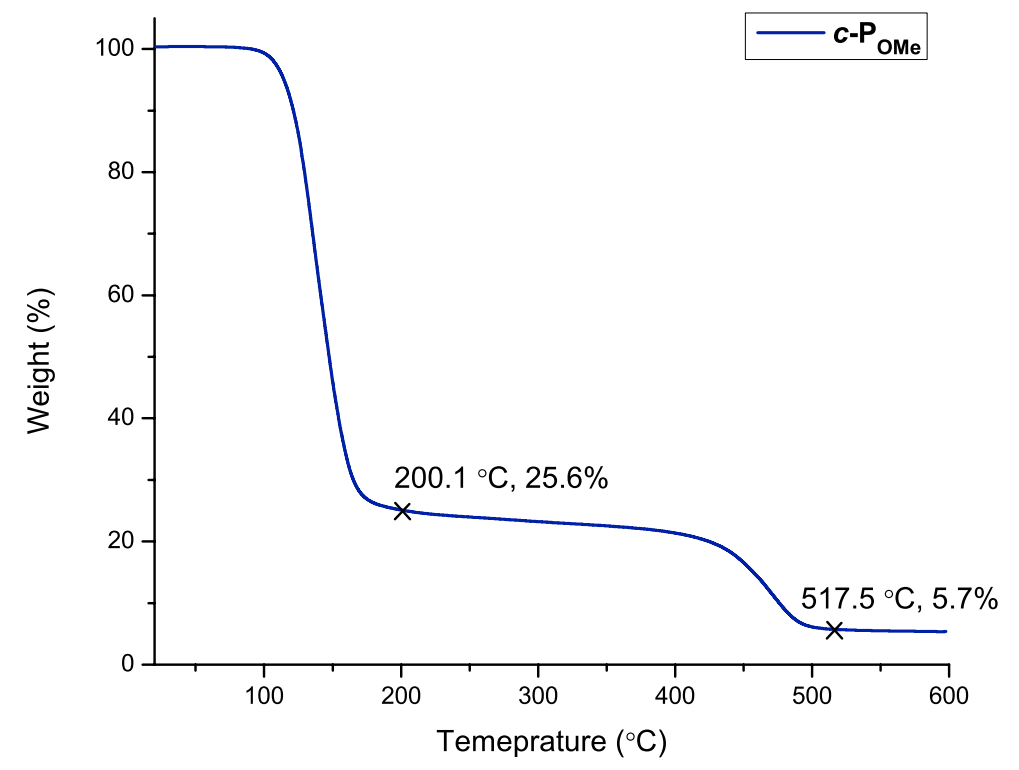

Figure S17. TGA curve of $\boldsymbol{c}$-Pome.

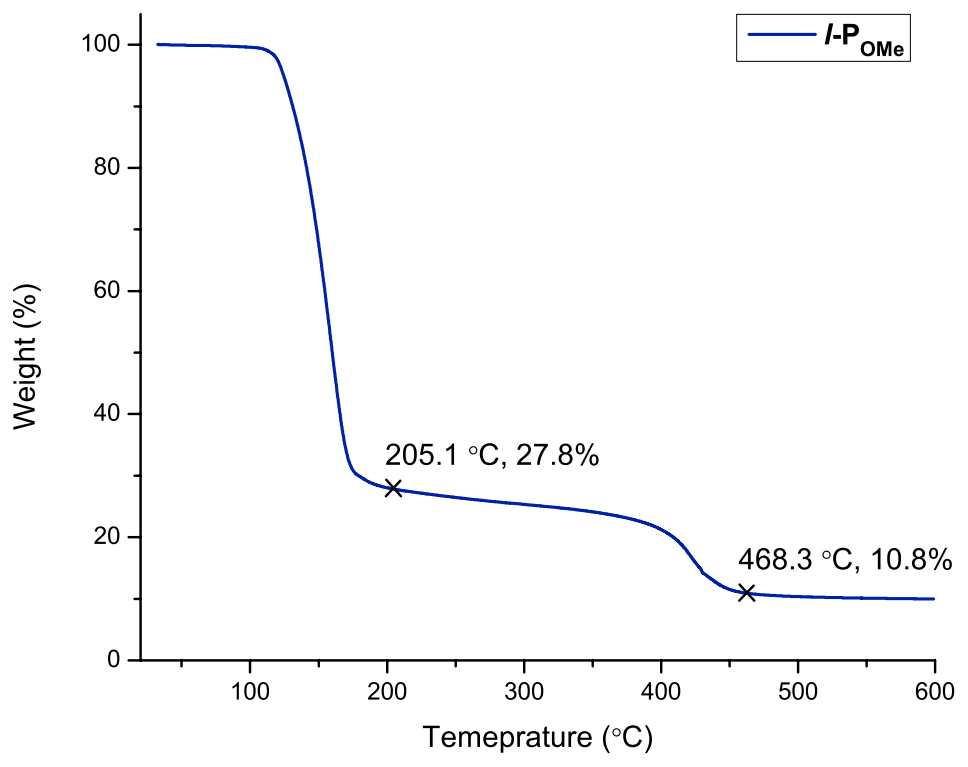

Figure S18. TGA curve of $\boldsymbol{I}$-Pome. 


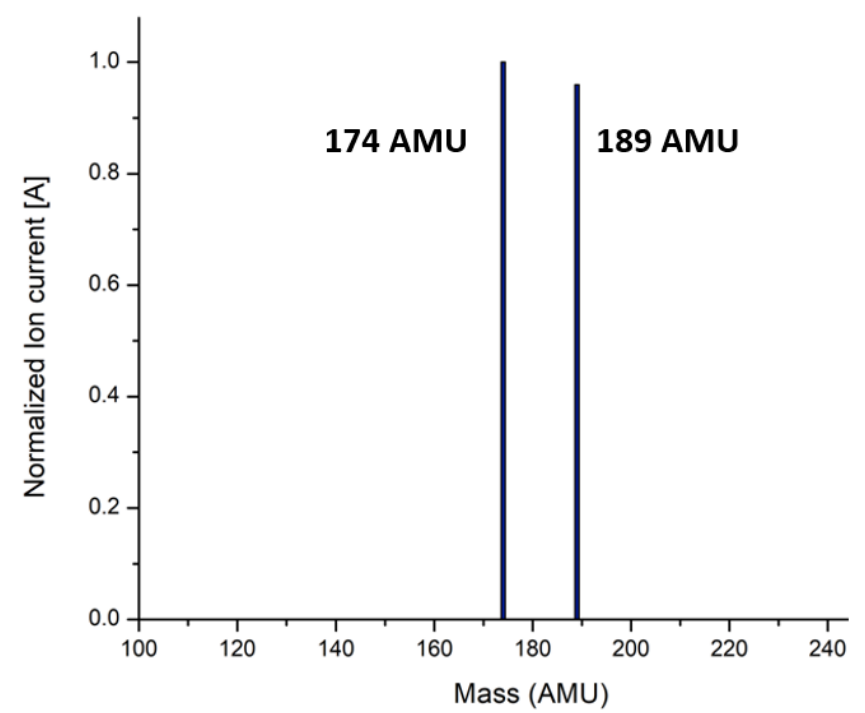

Figure S19. TGA-MS analysis of $c$-Pome

12. Differential scanning calorimetry

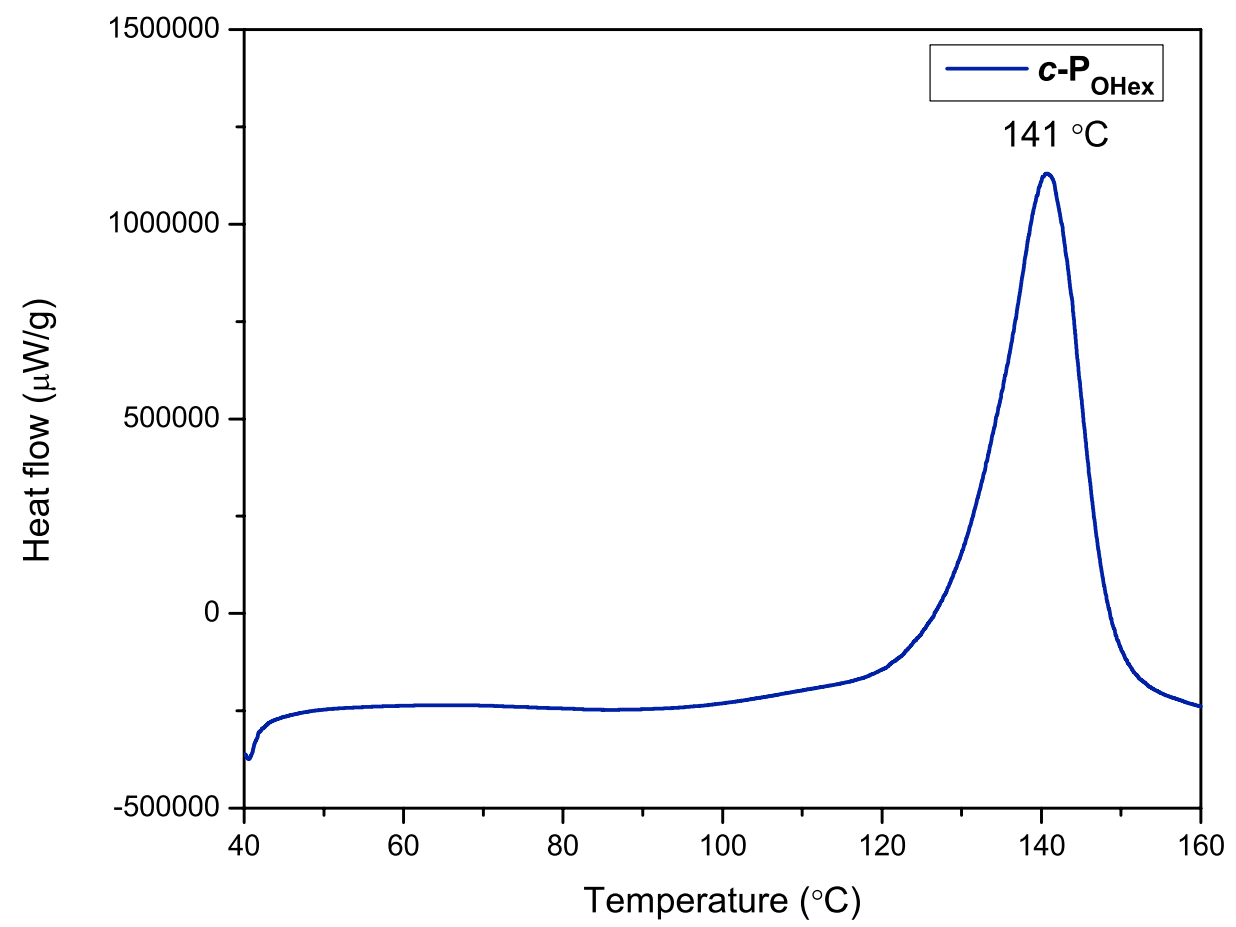

Figure S20. DSC curve of $\boldsymbol{c}$-Poнex. 


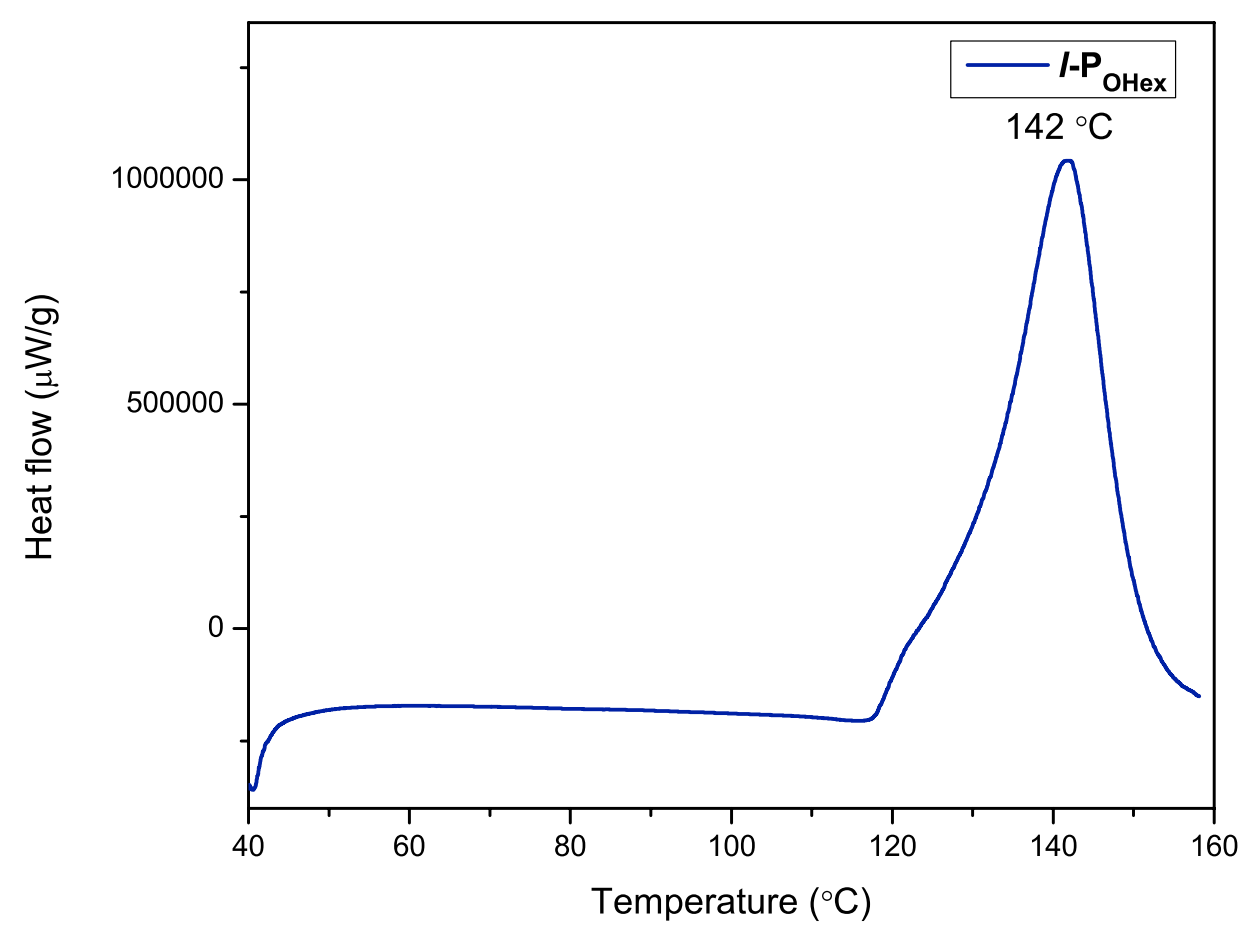

Figure S21. DSC curve of $\boldsymbol{l}$-PoHex. 
13. ${ }^{1} \mathrm{H}$ and ${ }^{13} \mathrm{C}$ NMR Spectra

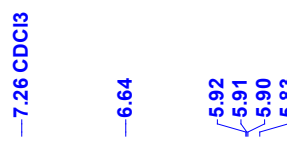

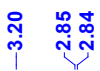

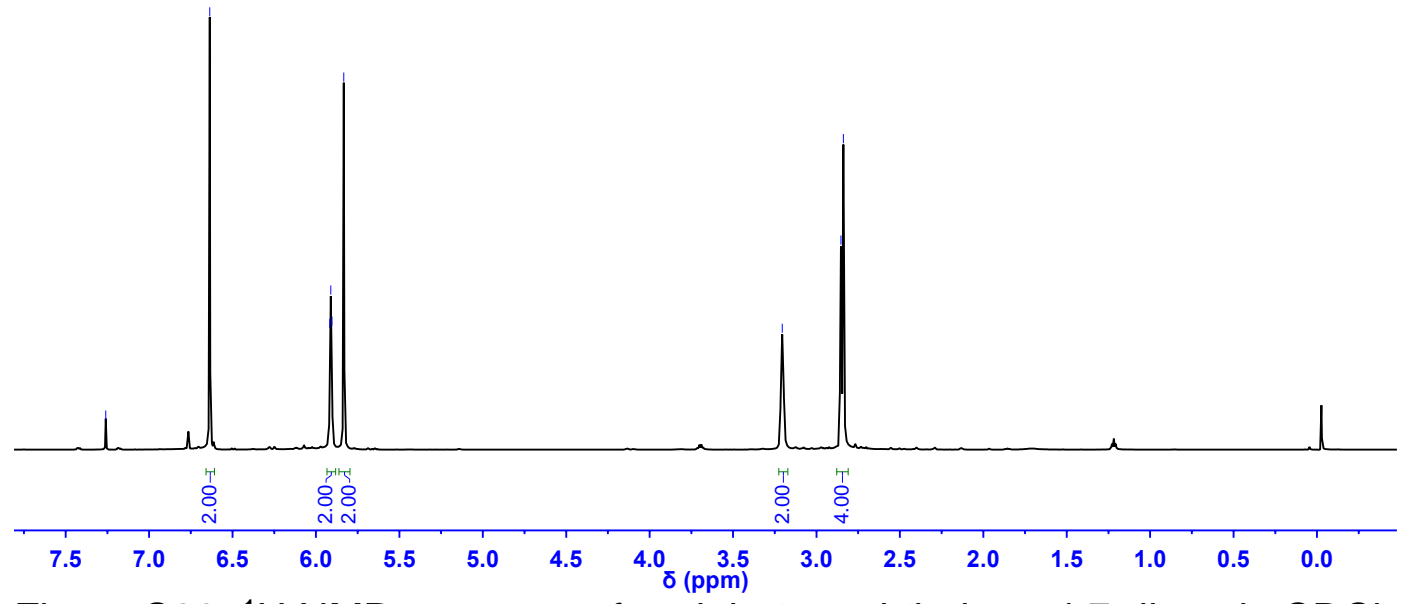

Figure S22. ${ }^{1} \mathrm{H}$ NMR spectrum of cyclobutanaphthalene-4,7-dione in $\mathrm{CDCl}_{3}$ at $25^{\circ} \mathrm{C}$.
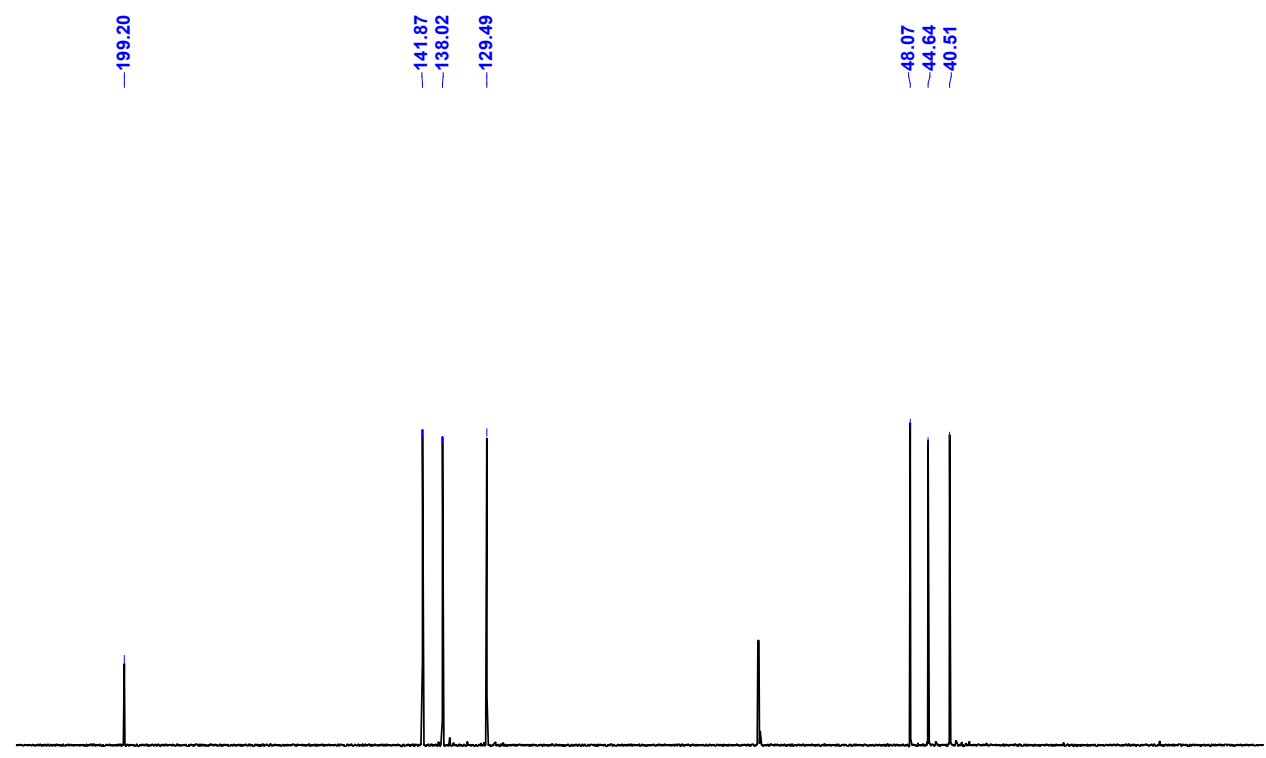

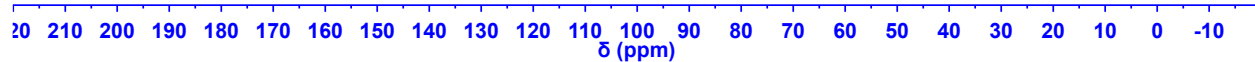

Figure S23. ${ }^{13} \mathrm{C}$ NMR spectrum of cyclobutanaphthalene-4,7-dione in $\mathrm{CDCl}_{3}$ at $25{ }^{\circ} \mathrm{C}$. 


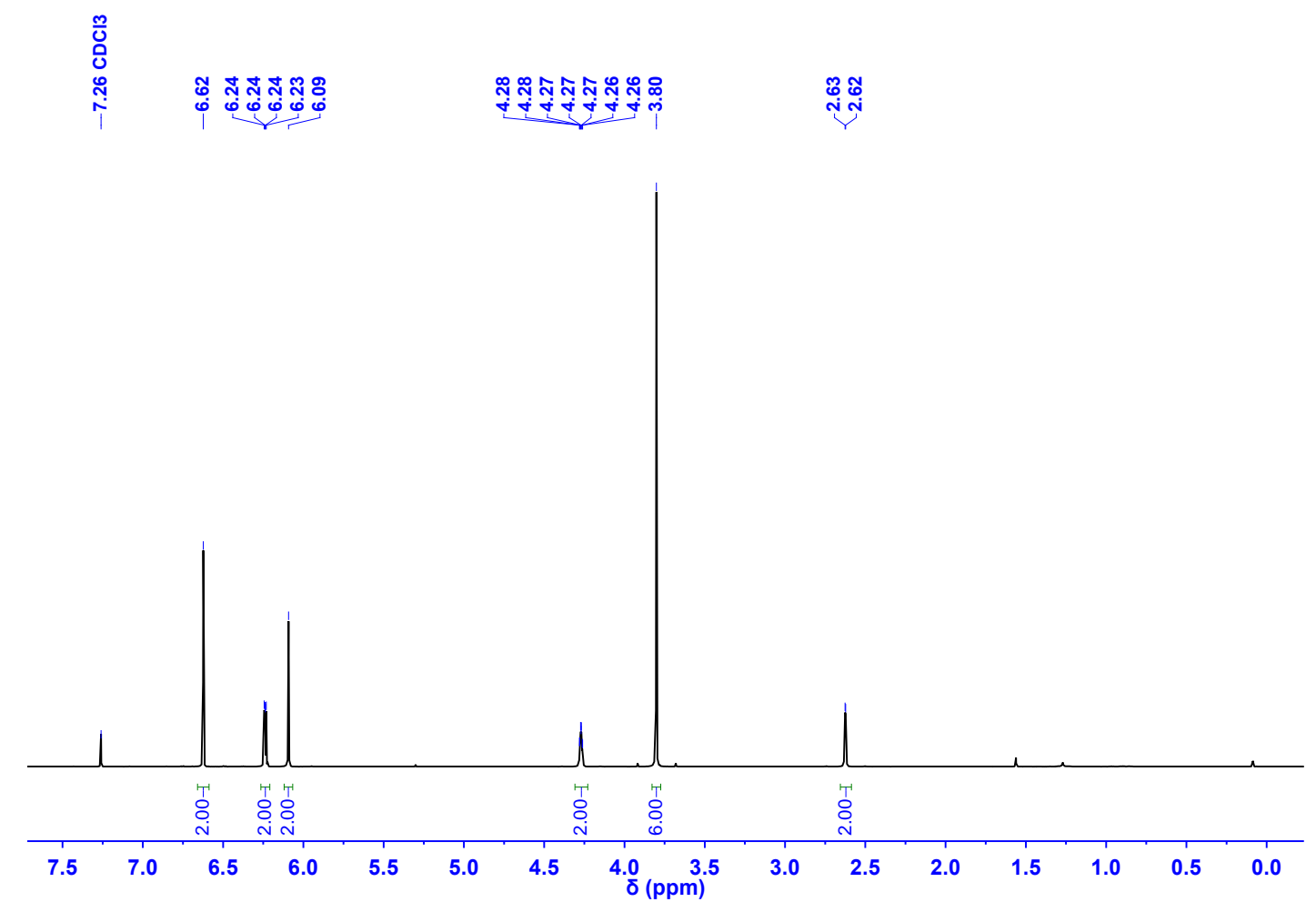

Figure S24. ${ }^{1} \mathrm{H}$ NMR spectrum of $\mathbf{M} 1$ in $\mathrm{CDCl}_{3}$ at $25{ }^{\circ} \mathrm{C}$.
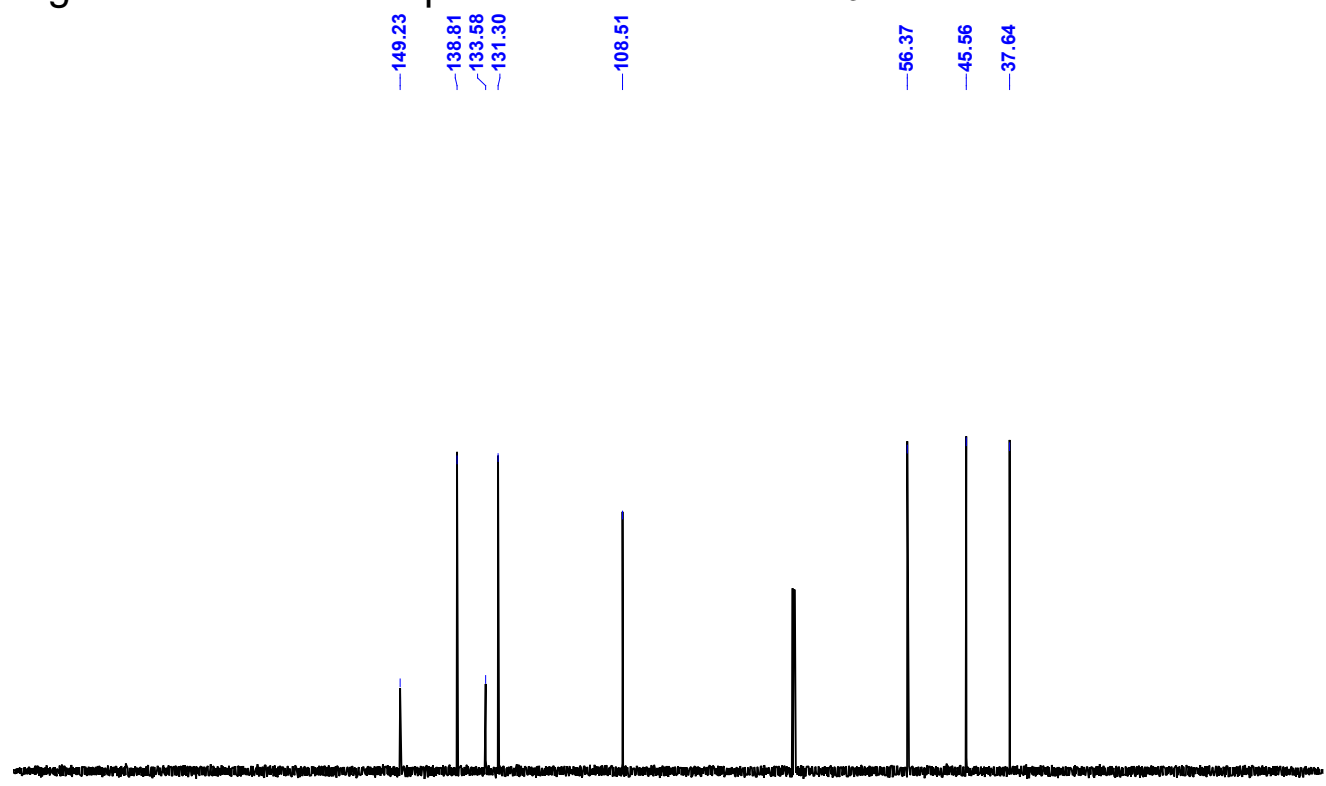

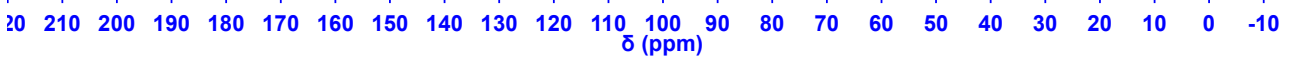

Figure S25. ${ }^{13} \mathrm{C}$ NMR spectrum of $\mathbf{M} 1$ in $\mathrm{CDCl}_{3}$ at $25^{\circ} \mathrm{C}$. 

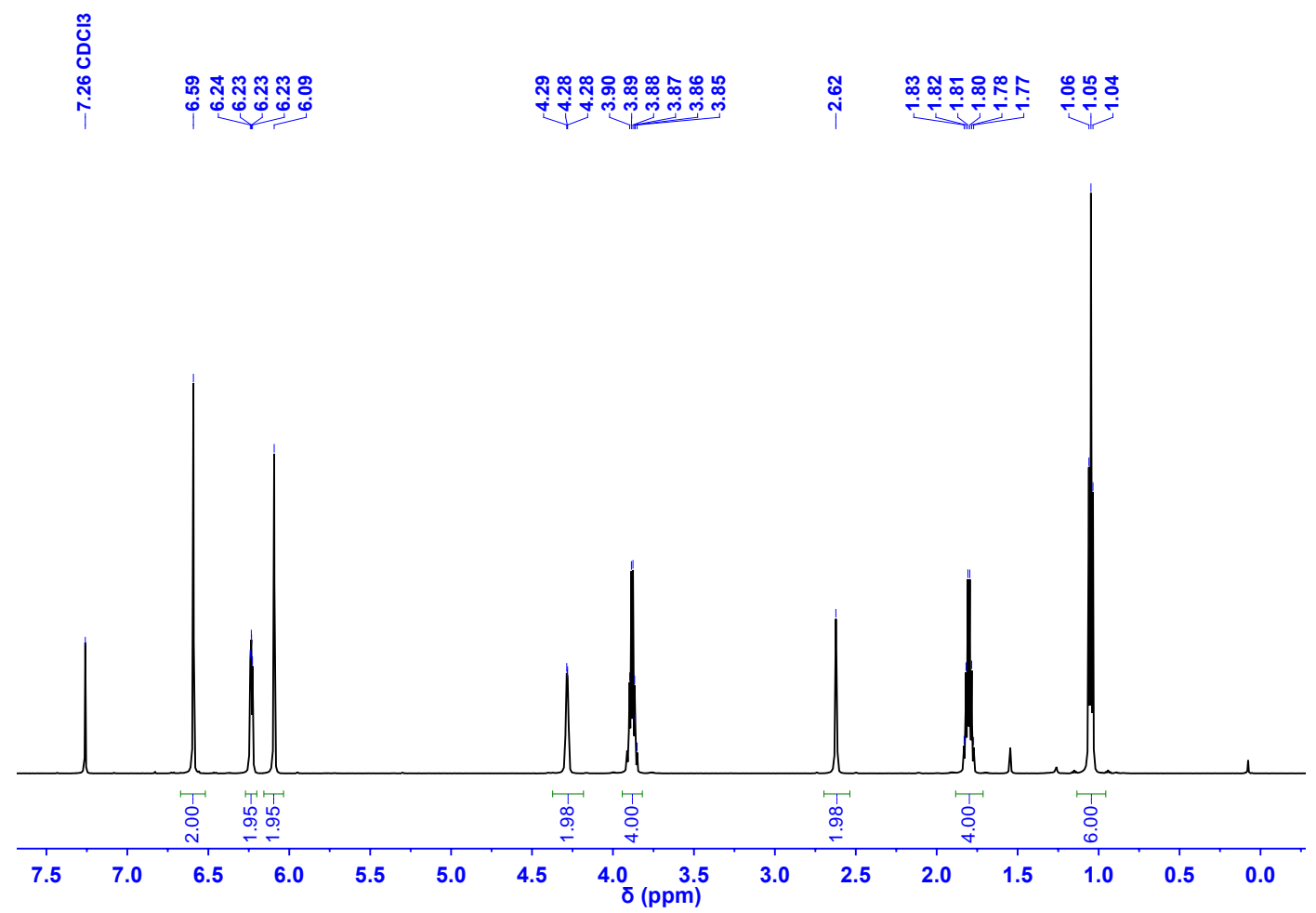

Figure S26. ${ }^{1} \mathrm{H}$ NMR spectrum of $\mathbf{M} 2$ in $\mathrm{CDCl}_{3}$ at $25{ }^{\circ} \mathrm{C}$.

\begin{tabular}{|c|c|c|c|c|}
\hline 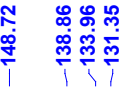 & $\stackrel{\stackrel{\varrho}{0}}{\stackrel{\rho}{\risingdotseq}}$ & $\stackrel{0}{i}$ & $\begin{array}{l}\stackrel{8}{0} \\
\stackrel{+}{+}\end{array}$ & 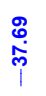 \\
\hline
\end{tabular}

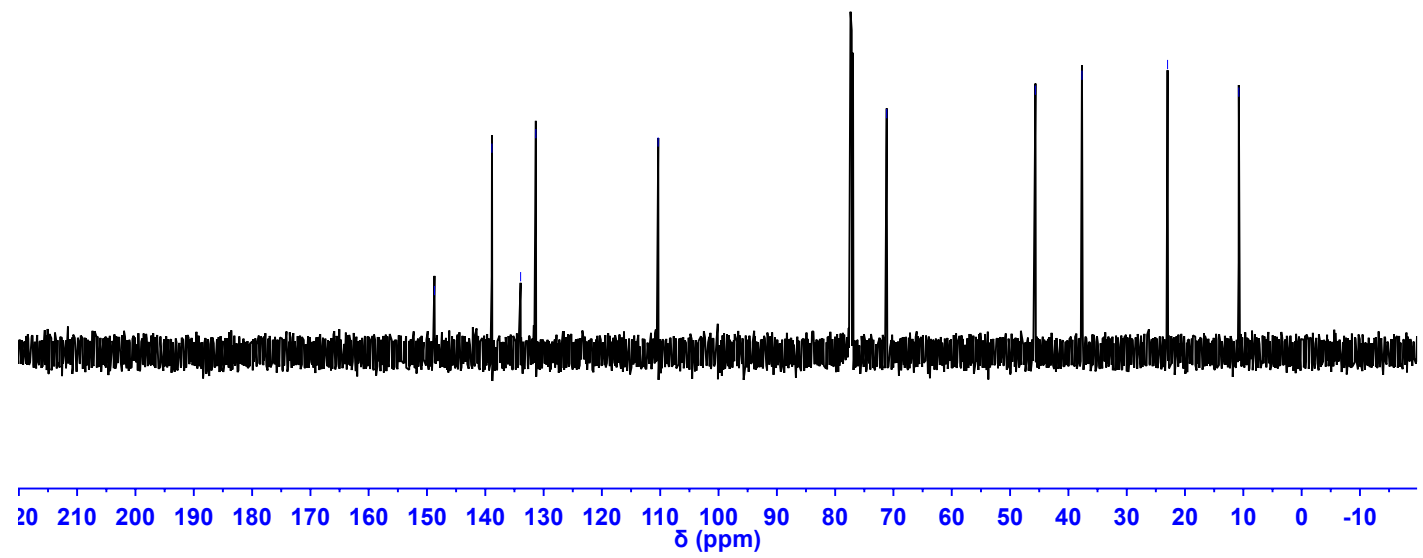

Figure S27. ${ }^{13} \mathrm{C}$ NMR spectrum of $\mathbf{M} 2$ in $\mathrm{CDCl}_{3}$ at $25^{\circ} \mathrm{C}$. 
$m$
0
0
$\stackrel{m}{0}$

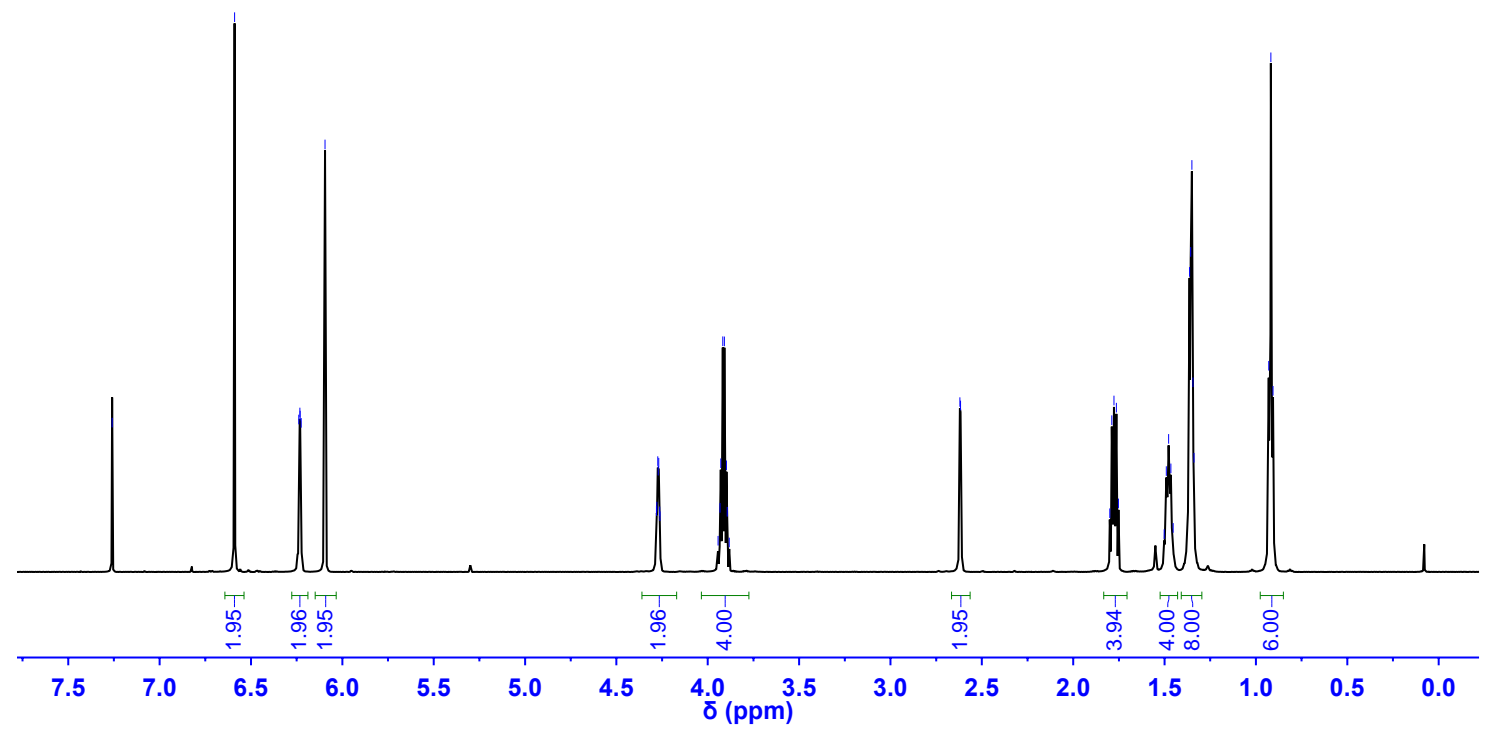

Figure S28. ${ }^{1} \mathrm{H}$ NMR spectrum of $\mathbf{M} 3$ in $\mathrm{CDCl}_{3}$ at $25^{\circ} \mathrm{C}$.

\begin{tabular}{|c|c|c|c|}
\hline 造 & $\stackrel{\stackrel{m}{0}}{\stackrel{0}{+}}$ & 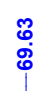 & 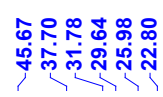 \\
\hline
\end{tabular}

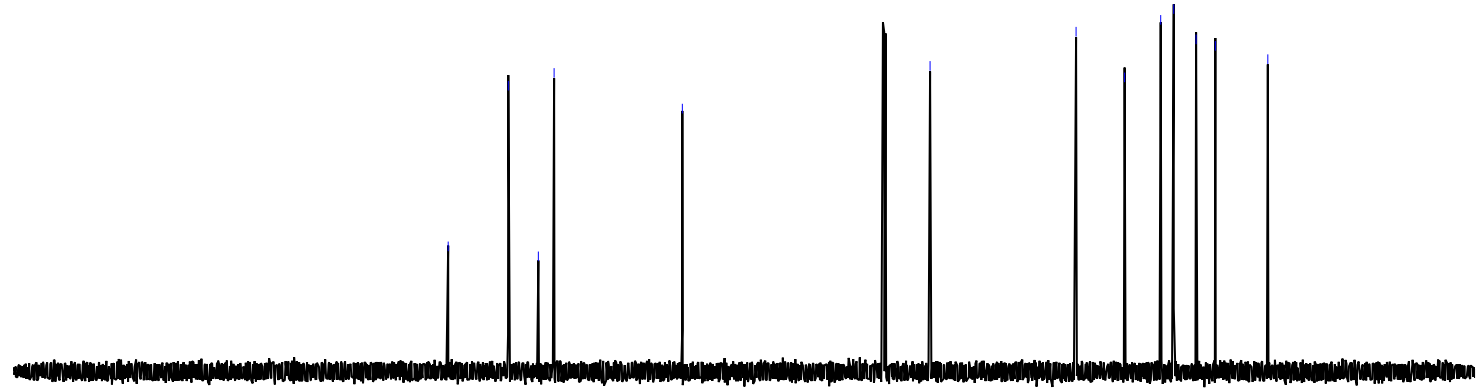

$\begin{array}{llllllllllllllllllllllll}20 & 210 & 200 & 190 & 180 & 170 & 160 & 150 & 140 & 130 & 120 & 110 & \underset{\delta}{(\mathrm{ppm})}(00 & 90 & 80 & 70 & 60 & 50 & 40 & 30 & 20 & 10 & 0 & -10\end{array}$ Figure S29. ${ }^{13} \mathrm{C}$ NMR spectrum of $\mathbf{M} 3$ in $\mathrm{CDCl}_{3}$ at $25^{\circ} \mathrm{C}$. 


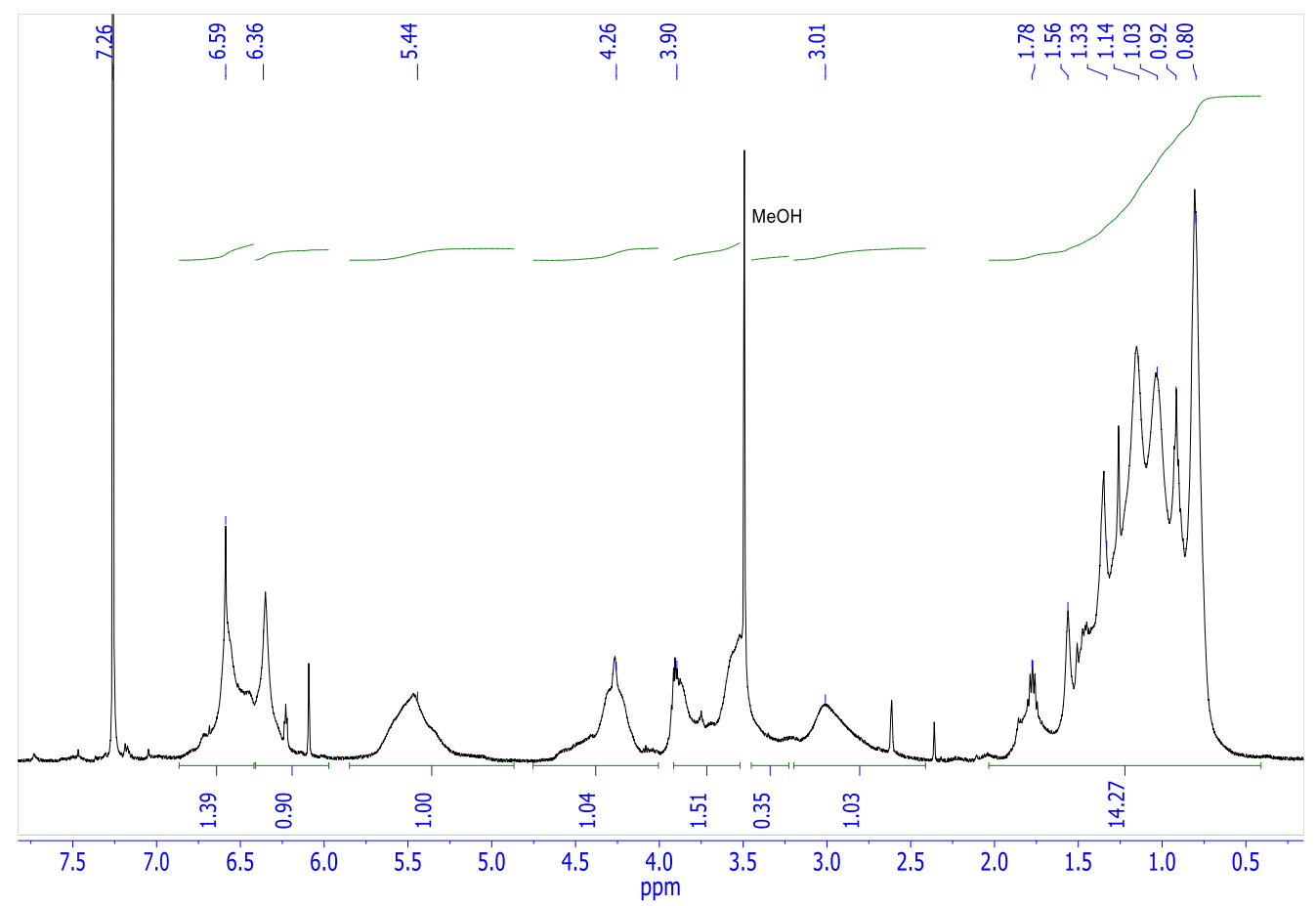

Figure S30. ${ }^{1} \mathrm{H}$ NMR spectrum of $\boldsymbol{c}$-P Pेех in $\mathrm{CDCl}_{3}$ at $25^{\circ} \mathrm{C}$.

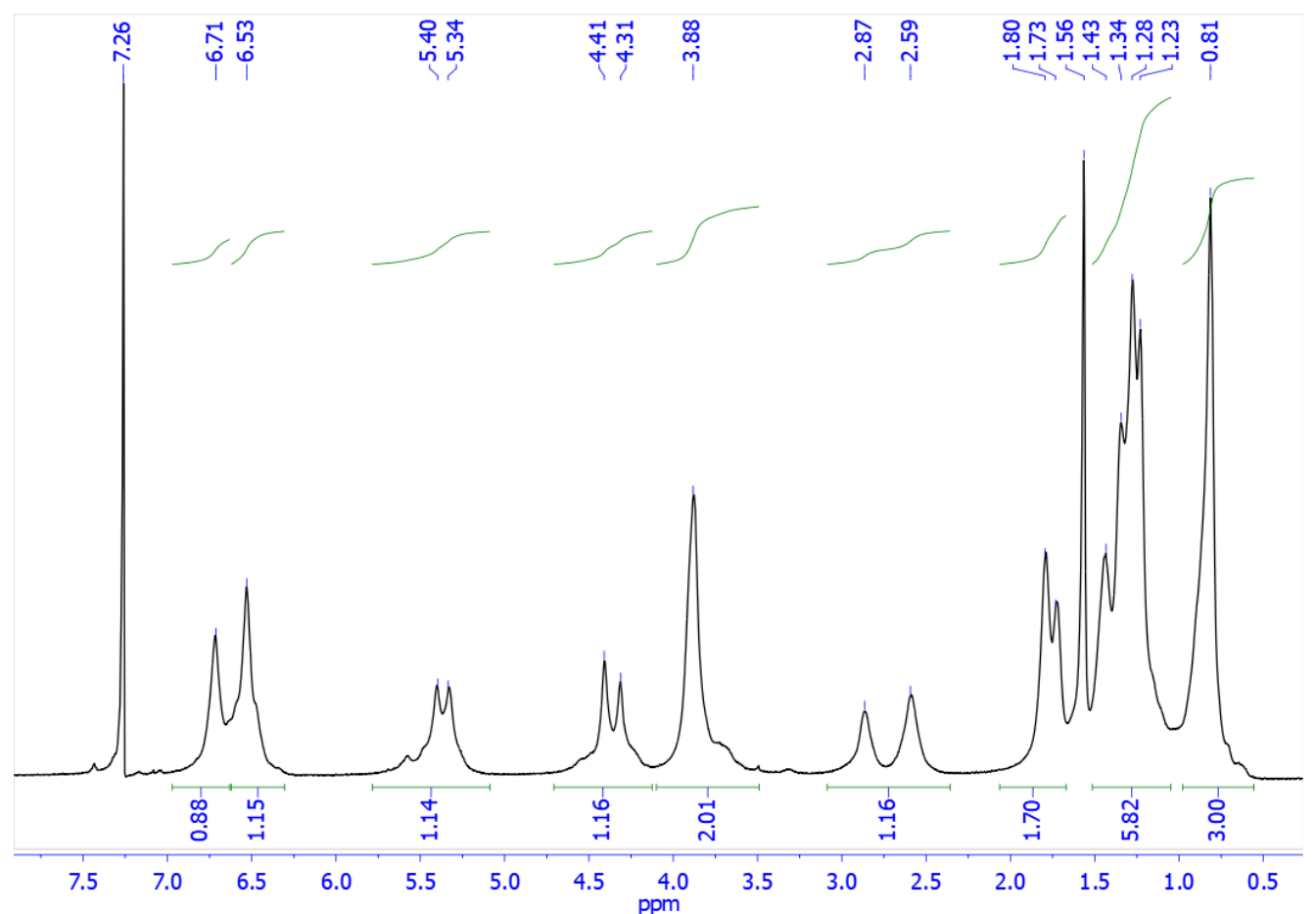

Figure S31. ${ }^{1} \mathrm{H}$ NMR spectrum of $\boldsymbol{l}-\mathrm{P}_{\mathrm{oHex}}$ in $\mathrm{CDCl}_{3}$ at $25^{\circ} \mathrm{C}$. 


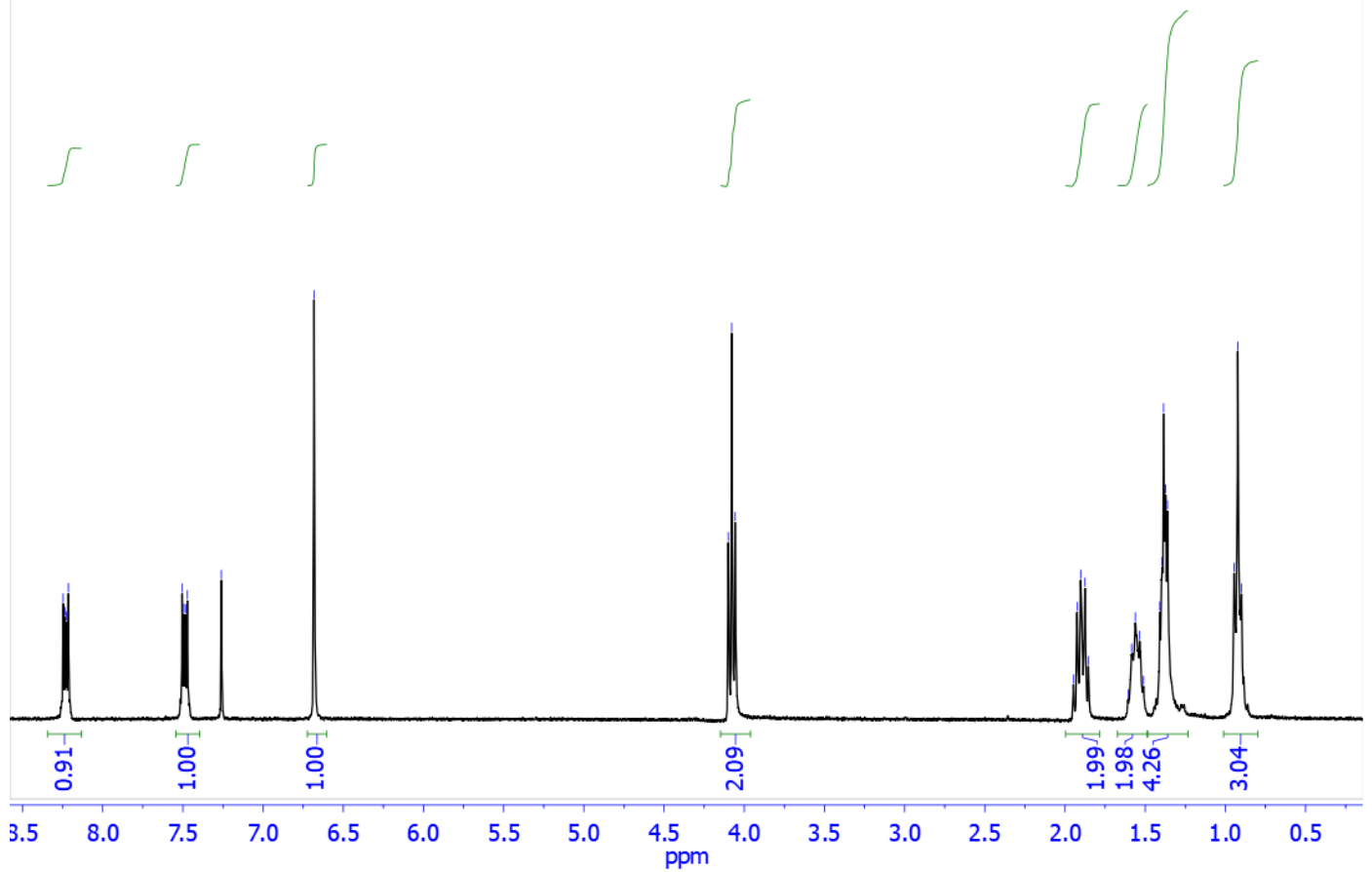

Figure S32. ${ }^{1} \mathrm{H}$ NMR spectrum of elminated 1,4-bis(methoxy)naphthalene in $\mathrm{CDCl}_{3}$ at $25^{\circ} \mathrm{C}$.

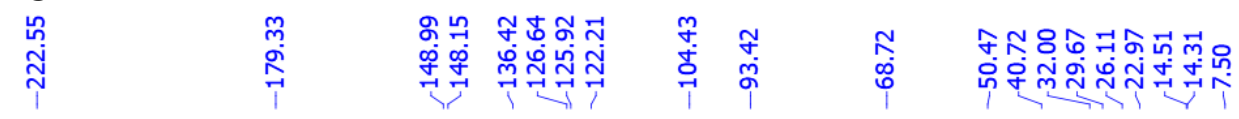

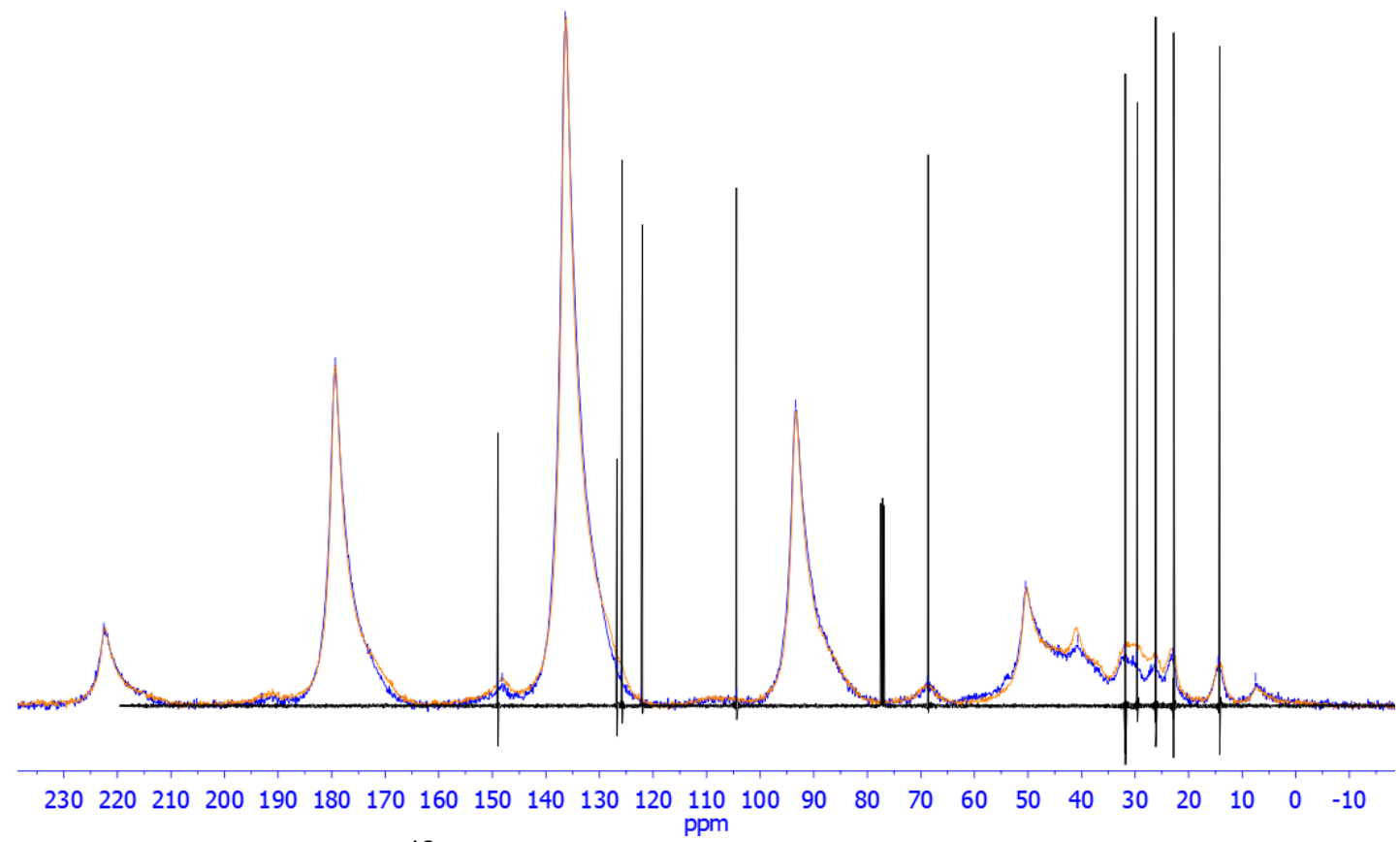

Figure S33. CP-MAS ${ }^{13} \mathrm{C}$ NMR spectra of $\boldsymbol{c}$-PA (blue) and I-PA (orange) generated from $\boldsymbol{c}$-PoHex and $\boldsymbol{c}$-PoHex, respectively, overlaped with ${ }^{13} \mathrm{C}$ NMR of $1,4-$ bis(hexyloxy)naphthalene (black) in $\mathrm{CDCl}_{3}$ at $25^{\circ} \mathrm{C}$. 


\section{Reference:}

(1)Sarkar, S.; McGowan, K. P.; Kuppuswamy, S.; Ghiviriga, I.; Abboud, K. A.; Veige, A. S., An OCO ${ }^{3-}$ Trianionic Pincer Tungsten(Vi) Alkylidyne: Rational Design of a Highly Active Alkyne Polymerization Catalyst. J. Am. Chem. Soc. 2012, 134, 4509-4512.

(2)Schaffer, H. E.; Chance, R. R.; Silbey, R. J.; Knoll, K.; Schrock, R. R., Conjugation Length Dependence of Raman-Scattering in a Series of Linear Polyenes - Implications for Polyacetylene. J. Chem. Phys. 1991, 94, 4161-4170.

(3)Chance, R. R.; Schaffer, H.; Knoll, K.; Schrock, R.; Silbey, R., Linear Optical-Properties of a Series of Linear Polyenes - Implications for Polyacetylene. Synth. Met. 1992, 49, 271-280.

(4)Schaffer, H.; Chance, R.; Knoll, K.; Schrock, R.; Silbey, R., Linear Optical Properties of a Series of Polyacetylene Oligomers. In Conjugated Polymeric Materials: Opportunities in Electronics, Optoelectronics, and Molecular Electronics, Springer: 1990; $365-376$.

(5)Brivio, G. P.; Mulazzi, E., Theoretical-Analysis of Absorption and Resonant Raman-Scattering Spectra of Trans- $(\mathrm{CH}) \mathrm{x}$. Phys. Rev. B 1984, 30, 876-882. 